MATCHING TREATHENT UITH RECURRENT ABDOMINAL PAIN SYMPTOHS: AN EVALUATIOH OF DIETARY FIBER AND RELAXATION TREATMENTS by

Mark Christopher Edwards

Dissertation submitted to the Faculty of the Virginia Polytechnic Institute and State University in partial fulfillment of the requirements for the degree of DOCTOR OF PHILOSOPHY

in

Psychol ogy

APPROVED:

Jack W Finnex Chailperson

Richard M. Eisler

Russell T.. Jones
Ross W( Gieene

Douglas R. Southard

October, 1989

Blscksburg, Virginia 


\title{
MATCHING TREATMENT UITH RECURRENT ABDOMINAL PAIN SYMPTOMS: AN EVALUATIOH OF DIETARY FIBER AND RELAXATION TREATMENTS
}

\author{
by \\ Mark Christopher Edwards \\ Jack W. Finney, Chairperson \\ Psychology \\ (Abstract)
}

Several etiological models of recurrent abdominal pain (RAP) in children have been proposed but no one model has been able to adequately account for the symptoms of all children with RAP. The present study proposed that symptom presentation may provide a basis for treatment selection. Two etiological models were tested in the present study: the constipation model and the operant learning model. Subjects were assigned to either model based upon whether or not they presented with symptoms of constipation. The treatments derived from these two models were: daily dietary fiber supplements, and teaching children relaxation skills and teaching parents to respond to their child's pain complaints by encouraging their child to cope with pain through relaxation. Thirteen subjects between the ages of $s i x$ and 12 years of age were treated in a nonconcurrent multiple baseline $A-B$ or $A-B-C$ design. To control for nonspecific 
effects, some subjects in each model received the treatment suggested by the alternative model first. All four subjects in the constipation model showed substantial reductions in stomachache activity following the introduction of the dietary fiber treatment. Of the nine subjects in the operant learning model, one showed substantial reductions in stomachache activity following the introduction of the relaxation and parent instruction treatment, two showed reductions during both treatments, four responded to the dietary fiber treatment, and two showed no response to treatment. Results support the effectiveness of a dietary fiber treatment for children with RAP with symptoms of constipation. Minimal support was obtained for the effectiveness of a relaxation and parent instruction treatment for children with RAP without symptoms of constipation. Limitations, implications and directions for future research are discussed. 
Acknowl edgements

I would like to dedicate this dissertation to my wife, - In many ways she has sacrificed more than I

throughout this project, as well as throughout my graduate career. I am grateful for her perseverance and support. I am looking forward to continuing to grow with her. Thank you

- I love you.

I would like to thank all the children and parents who participated in this project. without their cooperation this project would not have been possible.

I also want to thank my chairperson, Jack Finney, for his invaluable input and reedback throughout this project, as well as his wise counsel and mentoring during my last years in the program. I hope that we can contınue to work together on future projects.

I am also grateful to my dissertation committee members, Drs. Carlson, Eisler, Creene, Jones, and Southard. I appreciate the time that they spent reviewing the manuscripts. Their feedback had an important part in shaping this project. 
Table of Contents

LITERATURE REVIEW $\ldots \ldots \ldots \ldots \ldots \ldots \ldots \ldots$

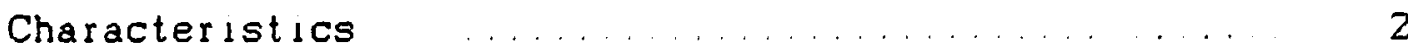

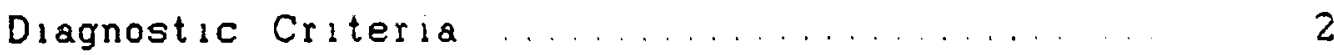

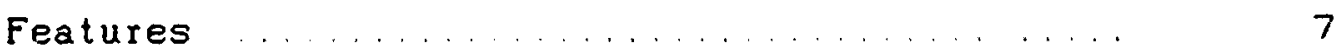

Natural Course of Recurrent Abdominal Pain ......... 13

Prevalence and Incidence................. 13

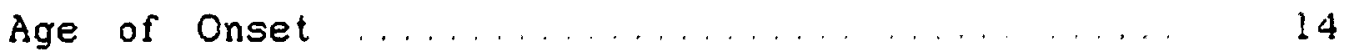

Prognosis and Natural History ............. Is

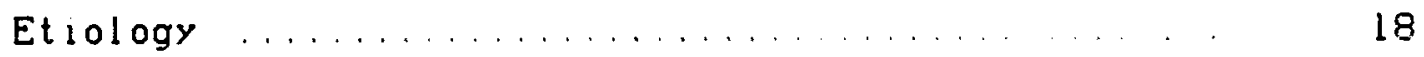

Physiological $\ldots \ldots \ldots \ldots \ldots \ldots \ldots$

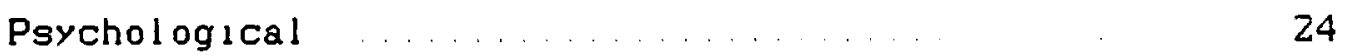

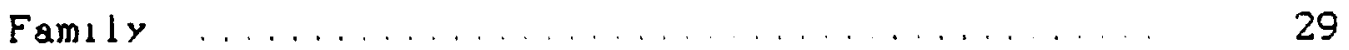

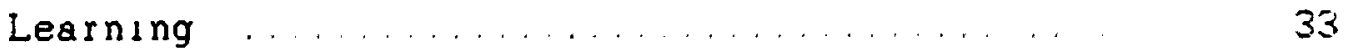

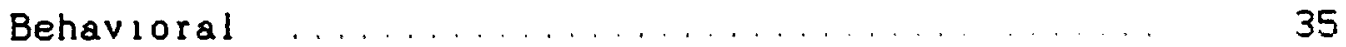

Issues of Continuity/Discontinuity $\ldots \ldots \ldots \ldots \ldots$

Treatment Studies of $\operatorname{RAP} \ldots \ldots \ldots \ldots \ldots \ldots \ldots \ldots$

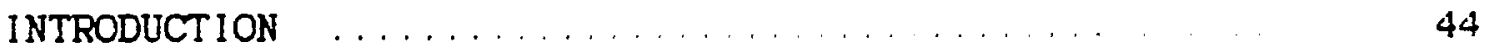

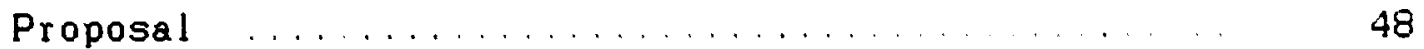

METHOD $\ldots \ldots \ldots \ldots \ldots \ldots \ldots \ldots \ldots \ldots \ldots \ldots$

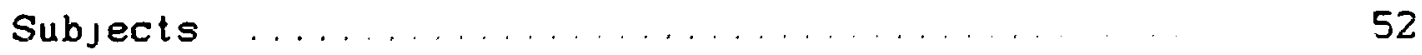

Messurement $\ldots \ldots \ldots \ldots \ldots \ldots \ldots \ldots \ldots$

Dependent Measures ........................ 58

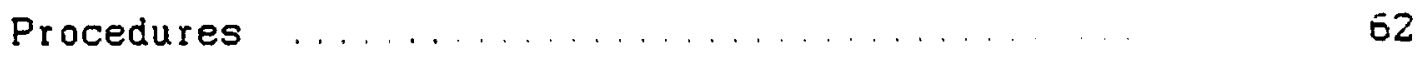

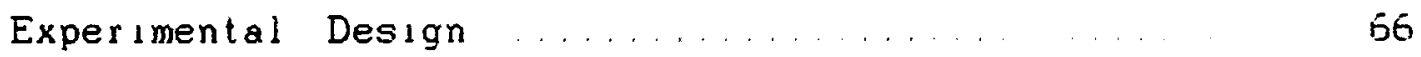




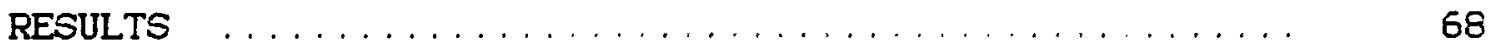

Subject Characteristics $\ldots \ldots \ldots \ldots \ldots \ldots \ldots \ldots \ldots, 68$

Treatment Outcome $\ldots \ldots \ldots \ldots \ldots \ldots \ldots \ldots \ldots \ldots$

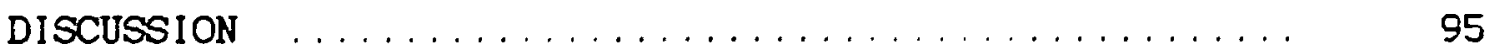

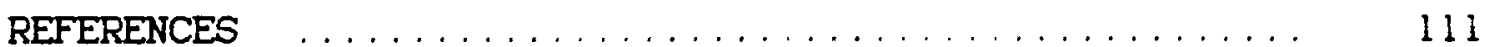

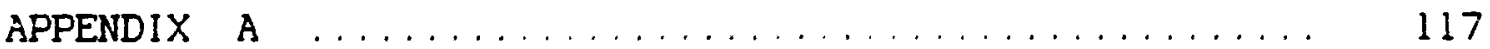

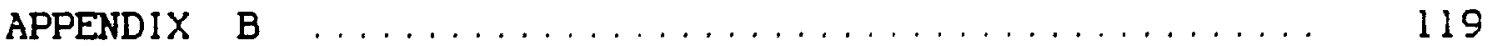

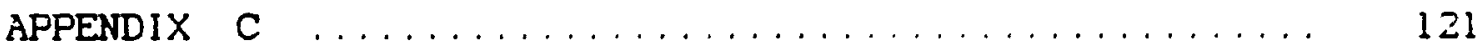

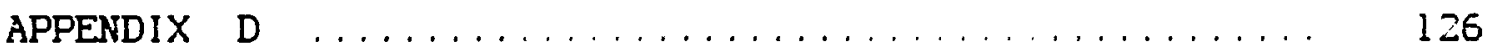

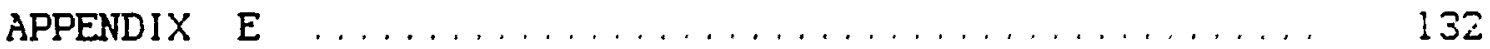

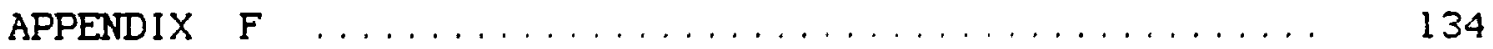

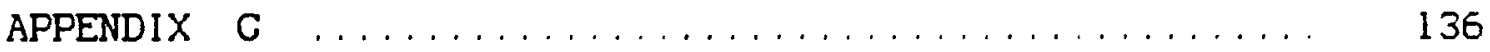

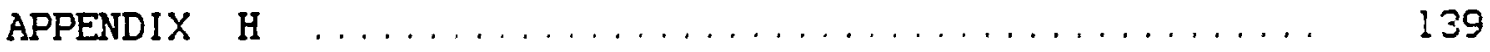

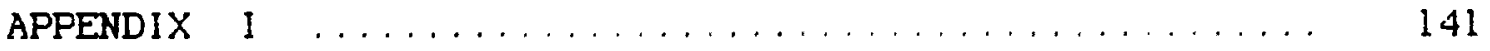

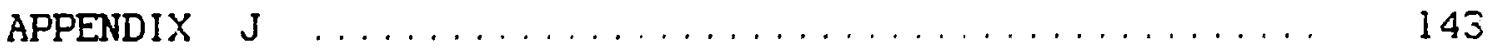

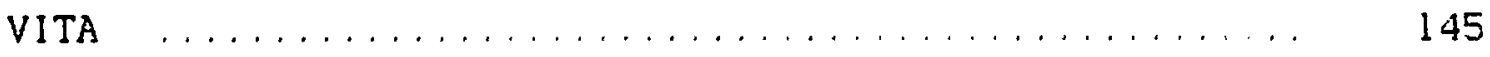


Table 1. Differential Diagnosis of Recurrent

Abdominal Pain $\ldots \ldots \ldots \ldots . \ldots \ldots$

Table 2. DSM III-R Classification of Somatoform

Disorders

Table 3. Incidence of Organic Disease in children with RAP

Table 4. Percentage of Children with RAP with

Associated Symptoms

Table 5. Percentage of Family Members with Pain

Complaints

Table 6. Subject and Therapy Characteristics of

the Sample

Table 7. Characteristics of Bowel Activity for

Constipated Subjects

Table 8. Characteristics of Bowel Activity for

Operant Learning Subjects

Table 9. School Absenteeism and Other Activities

Disrupled

Table 10. Percentage of Compliance with Treatments .

Table 11. Psychological Characteristics of the

Sample

Table 12. Additional Outcome Measures for Constipated Subjects 
Table 13. Additional Outcome Measures for Operant Learning subjects $\ldots \ldots \ldots \ldots \ldots \ldots \ldots$ 


\section{List of Figures}

Figure 1. Child-reported weekly stomachache

frequency for subjects in the constipation model

Figure 2. Child-reported weekly stomachache

frequency for subjects in the operant

learning model ................... 79 


\section{LITERATURE REVIEW}

Recurrent abdominal pain (RAP) is a functional gastrountestinal (CI) disorder typically defined as a syndrome in children three years of age or more who had at least three episodes of abdominal pain, severe enough to affect their activities, over a period longer than three months, without a known organic cause. RAP is the most common pediatric CI disorder (Whitehead, 1986 ). Epidemiologic information indicates that as many as $30 \%$ of school aged children will report stomach pains at some $t$ ime through thes school years and as many as $10 x$ to $15 \%$ of children suffer from recurrent stomachaches at any given point in time (Apler \& Naish, 1958, Oster, 1972). The recuring nature of the disorder can result in increased school absence, medical care utilization, and family disruption (Finney, Lemanek, Cataldo, Katz, \& Fuqua, 1989 , Fowler, Johnson, \& Atkinson, 1985

Since diagnosis of RAP is made by exclusion, that 15 , when no known organic cause can be found, the primary care physician can be taxed by the frequent visits of patients with RAP and the lingering question "Am I missing somethıng?" (Levine \& Rappaport, 1984). Little is known about the biological mechanisms involved in RAP. There $1 \equiv$ some correlational evidence for the involvement of psychological and learning variables; however, how these 
variables interact with biological variables to produce RAP symptoms is unknown. Furthermore, there are few well controlled treatment outcome studies to guide the clinical treatment of RAP. Given the high prevalence rates and the potential costs of RAP to children, families, and primary care practitioners, RAP represents a seriously understudied disorder. The purpose of the present study is to provide treatment outcome data which may help answer some questions regarding the mechanisms involved in the etiology and maintenance of RAP in children.

\section{Characteristics}

\section{Diagnostic Criteria}

\section{Diagnosis and Differential Diagnosis}

Diagnosis of recurrent abdominal pain (RAP) is usually made after a thorough physical examination and a careful history with attention to differential diagnosis and psychophysiological indicators (Poole, 1984). Physical examination should include rectal examination and stool hemocult test. If history and physical exam do not indicate organic disease, a minimal laboratory evaluation which includes complete blood count, sedimentation rate, urinalysis and urine culture should be sufficient to rule out organic disease. Additional laboratory investigations are indicated only when suggested by history, physical exam, or initial laboratory evaluation. Although the list of 
differential diagnoses is extensive (see Table 1), most organic disorders can be successfully screened with such an assessment .

Psychological and environmental factors have also been shown to be related to the development and maintenance of RAP; however, the absence of demonstrable organic pathology does not necessarily warrant the assumption that the basis of RAP is psychogenic (Bary \& Feuerstein, 1983; McCrath \& Feldman, 1986; McCrath, Goodman, Firestone, Shipman, \& Peters, 1983). Such a diagnosis would require evidence of psrchological and/or environmental factors which could account for the recurrent pain behavior in the child with RAP. Therefore, assessment should also examine psychosocial factors. Stress IApley, 1975; Hodges, Kline, Barbero, \& Flanery, 1984), family incidence of similar complaints. family incidence of other disorders, family pain models Apley, 1975; Christensen \& Mortensen, 1975; Osborne, Hatcher, \& Richtsmeier, 1989: Oster, 1972; Stone \& Barbero, 1970; Turner, 1978), pain proneness (Oster, 1972), excess parental anxiety (Hodges, Kline, Barbero, \& Woodruff, 1985), and maternal depression (Hodges et al, 1985) have all been shown to be associated with RAP. Additional psychosocial and psychophrsiological considerations will be discussed later in the paper.

Children with RAP that lack evidence of an organic 
Table 1

Differential Diaqnosis of Recurrent Abdominal Pain

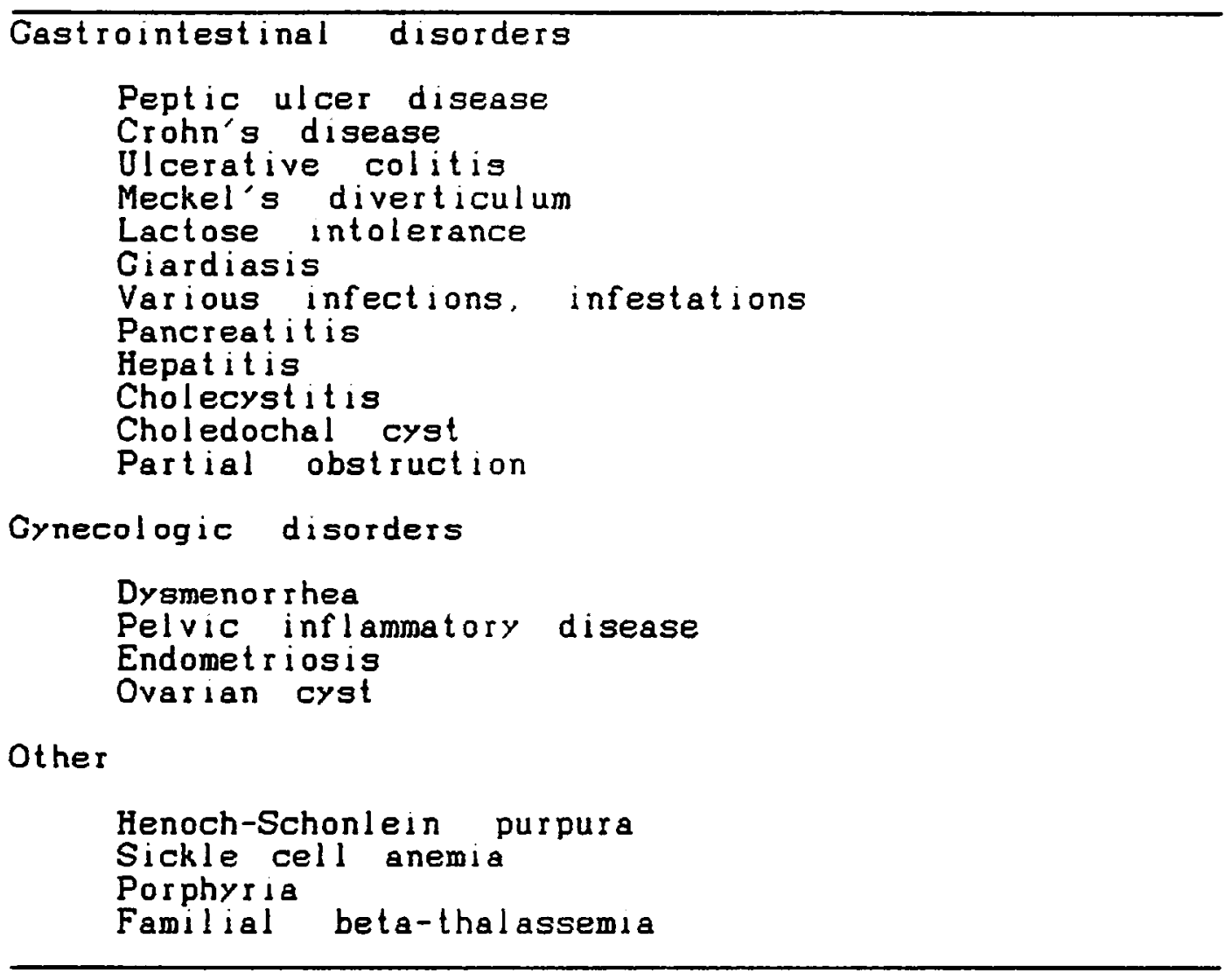

Note. From "Recurrent abdominal pain in childhood and adolescence" by S. R. Poole, 1984, American Family

Physician, 30 (2), p. 134 
pathology and show positive signs of a psychogenic process may meet criteria for a somatoform disorder. The current Diagnostic and Statistical Manual III-Revised (American Psychiatric Association, 1987) has defined seven types of somatoform disorders, each involving a presentation of physical symptoms without demonstrable organic pathology Table 2 provides a brief summary of diagnostic criteria for the somatoform disorders.

What about children with RAP that lack positive evidence of an organic or psychogenic process? Barr and Feuerstein (1983) suggested that the majority of children with RAP fall into this category. They proposed that these children be classified as dysfunctional. Potential mechanisms involved in these children will be discussed later in the paper.

Research criteria

Research has almost exclusively accepted Apley's operational definition (1975) of RAP. He limited the syndrome to children 3 years of age or more who had at least 3 episodes of pain that was paroxysmal in nature and severe enough to affect their activities, over a period longer than 3 months, and no known organic cause. 
Table 2

DSM III-R Classification of Somatoform Dieordere

Disorder Diagnostic Criteria

\begin{tabular}{ll}
\hline Body Dysmorphic & -preoccupation with imagined defect \\
Disorder & in appearance, or exaggeration of \\
& slight defect delusional \\
& -belief is not def \\
Conversion Disorder & - loss or alteration in physical \\
& functioning suggesting physical \\
disorder & -psychological factors etiologically \\
related to symptom development \\
-symptom not under voluntary control \\
-symptoms cannot be explained by a \\
known physical disorder
\end{tabular}

Hypochondriasis

-preoccupation with the fear of having a serious disease

- physical evaluation does not support the diagnosis

- persistant fear dispite medical reassurance

-duration of beliefs at least six months

Somatization Disorder -history of many physical complaints beginning before age 50 and persisting for many years

-at least 13 symptoms out of a list of gastrointestinal, pain, cardiopulmonary, conversion, sexual, or female reproductive problems

Somatoform Disorder

-preoccupation with pain for at least six months

-absence of organic pathology, or excessive impairment in relation to organic pathology

Undifferentiated Somat of orm Disorder

-does not meet criteria for somatization disorder

-presence if one or more physical symptoms

Somatoform Disorder Not-disorders with somatoform symptoms Otherwise Specified not meeting any other criteria 


\section{Features}

Characteristics of $\mathrm{Pain}$

Pain characteristics of children with RAP were described in two comprehensive studies IApley, 1975; Stone \& Barbero, 19701. Both samples consisted of about 100 children with a history of RAP which were hospitalized. The methodology used in these two studies has two disadvantages. First, the samples form a selected group, that is, the subjects were hospital patients and, therefore, are not likely to be as representative of the RAP population as would be an unselected random sample. Secondly, both studies lacked a comparison group of non-RAP children.

Description. In Stone and Barbero's sample (1970), 67x of the subjects described their pain as cramp-like, 18x ss dull, and 15x as acutely spasmodic. In Apler's sample (1975), 33x described their pain as a dull ache, less than 33x as colicky, and the remainder had idiosyncratic descriptions, such as, "sharp as needles" or "it feels like someone is burning toast in my tummy. "Apley also reported that the description of pain had no diagnostic significance.

Location. Fifty percent of the Stone and Barbero sample reported the location of the pain to be located in around the umbilical region, $20 x$ in the epigastric, eight percent in the infraumbilical region, and the remaining in the upper and lower quadrants. Two-thirds of the cases in Apler's 
sample were reported in the region of the umbilicus, $12 x$ Indicated both the umbilicus and epigastrium, $12 x$ to one side or the other from the umbilicus (usually right), and a small number indicated the epigastrium alone. Apley's data showed that organic disorders were more likely when the pain was peripheral than the more common central abdominal pair Intensity. Apley (1975) judged the degree of severity in his subjects both by description and the effects, such as whether the child stopped playing, lay down, went to bed, or cried. In his hospital-referred study, the pain was judgedd as mild in nearly half of the cases, severe in a quarter, and very severe in a quarter. In his survey of unselected school children with RAP, the number of severe cases was reported to be fewer. The severity of pain was not shown to be associated with any demonstrable organic pathology. In the cases where organic pathology was found, pain tended to be of constant or increasing severity across time.

In Stone and Barbero's (1970) sample, abdominal pain was reported to be erratic and variable with no consistent pattern of intensity. The intensity of pain could not clearly distinguish between those cases with organic pathology and those without.

Duration. Duration of pain was found to be considerably variable. The most common duration reported by Apley (1975) was pain episodes that lasted a total of a few to several 
minutes. These episodes consisted of short attacks of pain that lasting a few moments followed by pain-free intervals lasting several minutes. Occasionally the pain lasted several hours, and rarely for several dars. Some of the children reported a vague ache that was more present than absent, however, it was of such low intensity that activities were unaffected when the pain was present.

Stone and Barbero (1970) reported longer pain durations, with durations from five to 60 minutes in $37 x$ of their sample, one to three hours in $36 x$, and more than three hours in $27 x$.

Frequency. In Apley's (1975) hospital sample, $20 x$ reported that the pain occurred fairly regularly at intervals of a few weeks or months. In these children stomach pain was accompanied by other symptoms such as vomiting, headaches, and increased temperature. However, in most children pain frequency was variable. In some children pain occurred in single episodes with intervals of weeks, and in others many pain episodes would occur within a few days followed by long intervals in between. The frequency of pain episodes was not associated with incidence of demonstrable organic pathology.

\section{Presence of Organic Disease}

Organic causes which could account for the pain experienced in RAP children are discovered at the time of 
initial assessment in about three to seven percent of children (see Table 3). In an extensive investigation of 200 consecutive children referred to a hospital for abdominal pain. Apley (1975) reported that only 14 were found to have organic disorders thought to be causative, seven in the urogenital system and seven in the GI system. Turner (1978) evaluated 162 children seen in a general practice for complaints of recurrent abdominal pain and found five to have recurrent urinary infections.

Extensive work-ups are of ten conducted on children with complaints of RAP for fear of overlooking progressive organic illness (Stickler \& Murphy, 1979); however, longterm follow-ups of children diagnosed with nonorganic RAP show that organic disease is subsequently discovered in only two to six percent of the children (see Table 3 ). In a longterm follow-up of at least five years of children screened for organic pathology and diagnosed with RAP, Strickler and Murphy (1979) reported that only three had organic disease that had been missed by original evaluation. This low incidence of organic pathology was found despite the fact that $20 x$ of the patients had additional surgical procedures. Associated Symptoms

Table 4 sumarizes the incidence of associated physical symptoms from Apley's unselected school sample and hospital referred sample, Stone and Barbero's hospital-referred 
Table 3

Incidence of Organic Disease in children with RAP

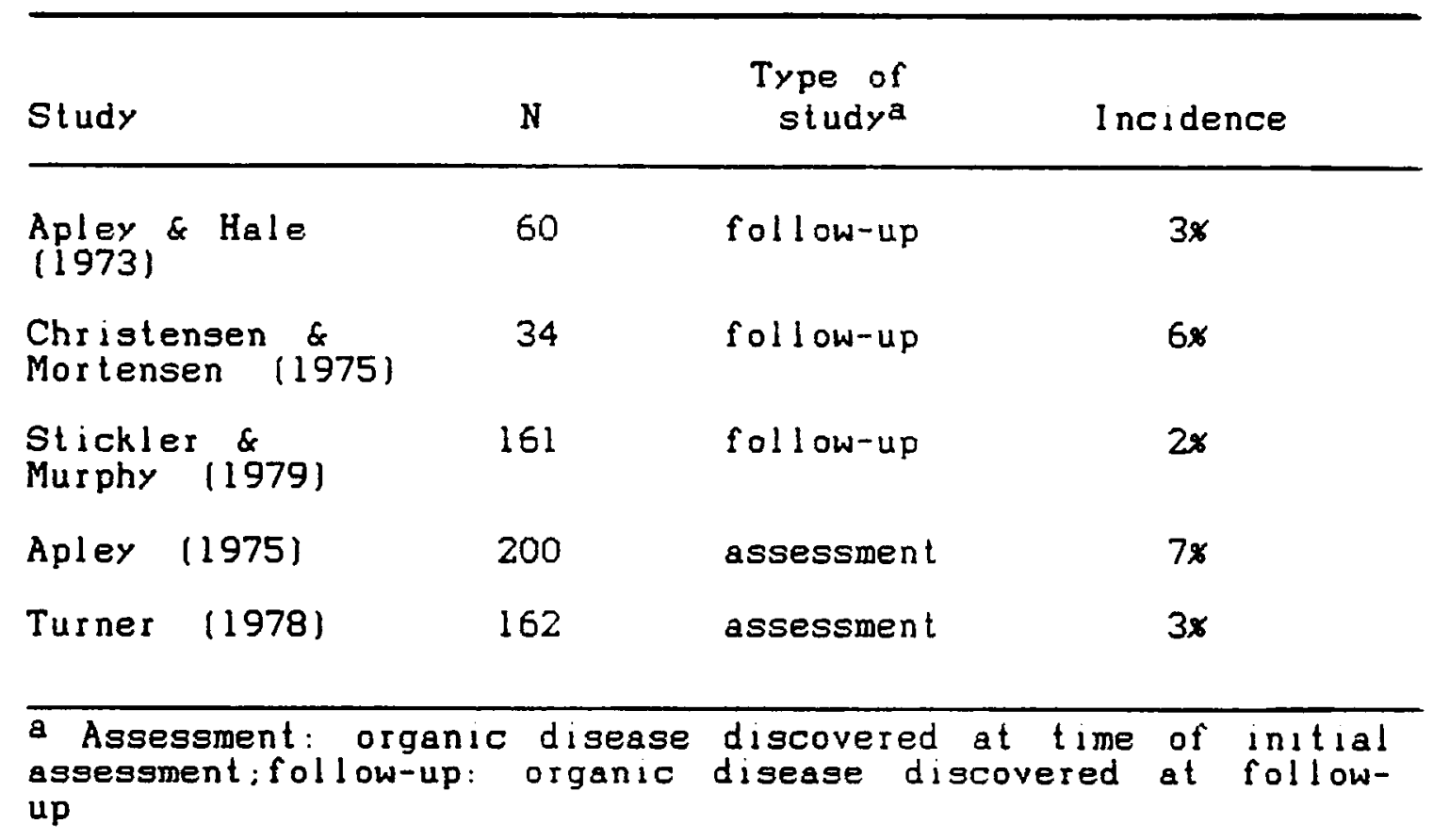


Table 4

Percentage of Children with RAP with Associated Symptoms

\begin{tabular}{|c|c|c|c|c|}
\hline Sympt oms & $\begin{array}{l}\text { Apley } \\
\text { School a } \\
(\mathbb{N}=1000)\end{array}$ & $\begin{array}{l}\text { Turner } \\
(N=162)\end{array}$ & $\begin{array}{l}\text { Stone \& } \\
\text { Barbero } \\
(N=102)\end{array}$ & $\begin{array}{l}\text { Apley } \\
\text { Hospital C } \\
(N=100)\end{array}$ \\
\hline Diarrhea & - & 7 & 18 & 4 \\
\hline Constipation & - & 2 & 31 & - \\
\hline Vomiting & 22 & 28 & 34 & 66 \\
\hline Headache & 23 & 18 & 50 & 20 \\
\hline Pallor & 38 & 13 & 41 & 50 \\
\hline Temperature & 11 & 3 & 16 & 5 \\
\hline Dizziness & - & - & 25 & - \\
\hline $\begin{array}{l}\text { Sleepiness } \\
\text { after at tacks }\end{array}$ & 26 & - & - & 25 \\
\hline Dilated Pupils & - & - & - & 3 \\
\hline Anorexia & - & 7 & 25 & - \\
\hline
\end{tabular}

Note. Children reported up to five symptoms each.

a nonselected sample (Apley, 1975)

b general practice sample (Turner, 1978)

C hospital referred sample (Apley, 1975; Stone \& Barbero, 19701 
survey, and Turner's (1978) general practice sample.

Natural Course of Recurrent Abdominal Pain Prevalence and Incidence

Apley and Naish (1958) reported a point-prevalence of RAP in a cross-sectional survey of 1000 unselected school children. Students from primary and secondary school were required to attend routine school medical examinations with a parent. A history was obtained from the mother as well as the child. Of the total, $10.8 x$ met criteria for RAP, with girls more affected than boys $112.3 x$ and $9.5 x$, respectivelyl.

In another survey with less stringent inclusion criteria, Oster (1972) reported on the incidence of RAP. headache, and limb pains in an eight-year prospective study using a nonselected population of school children. As the school medical officer, he examined and questioned school children during annual school medical examinations, He asked all children a routine question: "Do you suffer from tummy pains or headaches?" The author also stated that some answers were 'amplified', but did not specify the nature of this amplification. From an eight-year period, 18.162 individual observations were made 12200 to 2500 children on any given yearl. RAP was reported to be present in $14.4 \%$ of these observations, with girls more affected than boys (16.78 and 12.18 respectively). 
Prevalence rates have been shown to vary considerably across ages. Apley and Naish (1958) reported a falrly constant incidence of between $10 x$ and $12 x$ in boys from five to 10 years of age, followed by a decrease to about one percent at age 13, followed by a second peak to $10 x$ at age 14. In girls, the incidence rate was about $12 x$ from five to eight years of age, followed by a sharp rise to about $28 x$ occurred at age nine, with a subsequent steady decrease through age 15. Oster (1972) showed similar incidence rates. In his longitudinal study, a maximum rate of $21 x$ for boys and $30 x$ for girls was reached at the age of nine years after which it decreased steadily to approximately five percent at 16 to 17 years.

In summary, prevalence of RAP appears to be between $10 x$ and 15x, with girls showing consistently higher prevalence rates than boys. Prevalence rates show considerable variability across age ranges, peaking at about nine years of age with incidences between $12 x$ and $30 x$.

\section{Age of Onset}

In Apley's (1958) hospital sample $(N=118)$, there was a steady rise in the number of children with RAP onset in both sexes up until the age of five years. In boys, the numbers steadily decrease through 15 years. In girls, the numbers decrease after age five with a sharp increase occurring 
between eight and 10 years (comprising nearly half the sample).

In a general practice sample of 155 children with RAP between the ages of three and 15 rears (Turner, 1978) a different pattern in age of onset was found. The number of boys with RAP onset gradually increased up until age seven and then gradually declined through age 15. In girls, there was a sharp increase up to age six, declining through age 11. peaking again at age 12, and then declining through age 15.

In these two series the patterns in age of onset were quite different. It should be noted, however, that the differences may represent differences in selected and unselected samples.

\section{Prognosis and Natural History}

It appears that the symptoms of many children with RAP abate with time. Stone and Barbero (1970) reported on the short term course of 102 hospital-referred children with RAP. In their sample, most of the patients had active pain symptoms at the time of hospitalization, with durations as follows: $14 x$ less than one month, $31 x$ one to six months, 19x six months to two years, and $16 x$ more than two years. During their hospitalization, 53x showed a total abatement of intestinal symptoms and $38 x$ showed declines in 
symptomalogy. However, it is difficult to determine the long term course of the disorder without extended follow-up.

Apley and Naish (1959) followed up the progress of 30 patients who were hospitalized as children with recurrent abdominal pain eight to 20 years earlier. Eighteen controls who had attended the same hospital at about the same time with trivial disorders were randomly selected and matched with the first 18 RAP patients for age and sex. Among the RAP patients, nine cases became symptom free; in nine cases episodes of abdominal pains had ceased, but other symptoms developed, among which headaches were the most common; and in 12 cases abdominal pains persisted, mostly accompanied by additional symptoms, among which 'nervous' complaints were the most common. Among the 18 controls, one had severe headaches, four had occasional slight headaches, three had abdominal discomfort, and one suffered from "bad nerves". Apley and Hale (1973) reported on a follow-up of 30 patients who had been referred to a hospital with RAP and who had been treated with reassurance and explanation. Length of follow-up between 10 and 14 years. In nine of 30 cases abdominal pains had ceased and no other symptoms were reported; in 10 cases abdominal pains had ceased but other symptoms had developed le.g., headaches, dysmenorrhea, other pains, other bodily symptoms, "nerves"); and in the remaining 11 , some abdominal pain continued into adolescence 
or early adulthood. These results are almost identical to their first study. Nearly a third had lost all symptoms; in another third abdominal pains ceased, but other symptoms continued; and in another third abdominal pains persisted with most accompanied by additional symptoms.

Christensen and Mortensen (1974) conducted a controlled follow-up investigation of 34 hospital-referred children diagnosed with RAP 27 to 30 years earlier. Controls consisted of persons born at about the same time as the RAP group, excluding those with apparent abdominal pain. randomly selected from public registration files. Both groups were assessed with questionnaires. Significantly more RAP patients had suffered from recurrent abdominal pain as adults than controls, 18 of 34 (52x) and 13 of 45 (28x), respectively. Eighteen of the original 34 RAP patients were contacted and given a detailed interview and clinical examination. Of these 18, 11 had a clinical picture of irritable colon, five with both irritable colon and peptic ulcer/gastritis, and two with duodenal ulcer. Other symptoms were also more common in RAP patients than controls, including headaches, back pain, 'bad nerves', or grnecological symptoms. Eleven of the 34 RAP patients had other symptoms compared to only six of the 45 controls. The long-term follow-up data on the course RAP in children suggests that in adulthood about one-third are 
completely pain free; about one-third develop other nongastrointestinal symptoms; and about one-third experience continued abdominal pain.

\section{Etiology}

\section{Physiological}

\section{Lactose Intolerance}

A phenomenon that occurs normally in many preschool children is malabsorption of lactose as a result of maturational decline in functional lactose activity (Barr. Levine, \&atkins, 1979). This malabsorption may result in abdominal pain, diarrhea, abdominal bloating, and excess flatulence. Bayless and Huang (1971) have suggested that milk and lactose intolerance be considered as a factor unrelated to disease which might cause RAP symptoms in some children.

Evidence has been inconsistent for the role of lactose intolerance in RAP children. In an uncontrolled study, Barr et al. (1979) tested 80 children with RAP and found that $40 x$ were lactose malabsorbers. Twenty-eight of these malabsorbers were then given a lactose diet trial in a $B A B$ design (elimination diet - normal diet - elimination diet). Twenty (71x) of these children experienced greater pain during the lactose periods. In another controlled study, Liebman (1979) found that 29x of the RAP children were lactose malabsorbers, as compared to only three percent of 
the control children. An uncontrolled lactose-free diet trial with malabsorbers showed significant relief of pain in 91x $(10$ of 11$)$. However, in double-blind controlled study utilizing diets that contain either a cow's milk formula or a soybean formula, Lebenthal, Rossi, Nord, and Branski (1981) found that: I) the prevalence of lactose intolerance was no different between RAP children and controls; and 2) lactose-intolerant children did not respond any better to the lactose-free diet than children who were lactose tolerance. At the present time, the inconsistent data regarding lactose intolerance in $R A P$ children does not support its role as a major cause of RAP symptoms. Autonomic Instability

Differential autonomic nervous system reactivity has been proposed as an individual characteristic that might differentiate RAP children from healthy children. Four experimental studies have examined specific autonomic functioning in RAP children. Kopel, Kim, and Barbero (1967) reported increased motility in the distal colon following subcutaneous injection of neostigmine (parasympatho-mimetic) in RAP children when compared to healthy children. This finding suggests that RAP children may have increased sensitivity to parasympathetic stimulation. Rubin, Barbero, and Sabinga $\{1967$ ) used pupillary response as an index of parasympathetic-sympathetic nervous system reaction. In 
response to a cold-pressor task, they found that RAP children had prolonged recovery time, but found no differences in resting levels and response to stress. In an attempt at replication, Apley, Haslam, and Tulloch (1971) failed to replicate the recovery time deficit but did describe a more "unstable" recovery in the RAP and emotional problem groups than in the health control group.

A more recent attempt was made by Feuerstein et al. (1982) to examine the nature of the recovery response in children with RAP. They compared autonomic (peripheral vasomotor, and heart rate), somatic (forearm EMG), behavioral (facial expression), and subjective (pain intensity and distressl responses in an $A B A$ design utilizing a one minute cold press task in RAP, chronic non-pain, and healthy children. They found no differences between groups on any of the response measures. In summary, the evidence regarding an autonomic nervous system deficit in children with RAP is mixed and does not allow for firm conclusions. Colonic Motility

The phrsiology of the colon or large intestine is the least understood region of the gastrointestinal tract (Milla, 1988). The colon is made up of three segments: the ascending. transverse, and descending colon. The functions of the colon are to: 1) reabsorb water. 2) to hold fecal material prior to defecation, and 3) to control defecation. Flow through the colon 
is slow, particularly in the ascending and iransverse colons where there 1 e relatively litlle contractile actioly except jo: once or twice a day. This activity is characterized by brief propulsive episodes which sweep material into the descending colon. The motility of the descending colon ls characterized b; nonpropulsive contractile activity. The purpcse of this activit: appears to be to retard the passage of gas and stool to the rectum until defecation. Increased motllity of the descending colon is associated with constipation while decreased mot: $:$ i: is associated with diarthea lWhtehead and Schuster, icesi

Both the sympathet 10 and parasymathetic ne:vous systems innervate the colon. In general, parasmpatinet: activity results in increased motility in the distai coion, whereas, sympathetic activity results in decrease mot:iliy Paradoxically, symptoms of irltable bowel syndrome IIES are thought to be stress related, which is a sympathet: response, however IBS Involves increased disial bowei motlilty, a parasymathetically mediated effect.

Aduits with iritable bowel syndrome have been shown to have an excess number of nonperistaltic, segmental contractions in the distal $25 \mathrm{~cm}$ of the bowel. Latimer and his colleagues ILatimer, Sarna, Cambell, Latimer, wateriall, \& Daniel, 198il compared the colonic motility of iEs patients with psrchiatile outpatients with no IBS simptoms and normal controls and found that IBS had more coion: 
motility than normals and that the psychiatric controls had intermediate amounts of motility. Adults with IBS have also been shown to have increased colonic activity in response to a variety of stimuli including emotional arousal (Almy. 1951), eating (Connel1, Jones, \& Rowlands, 1965), and balloon distention Chasen, Tucker, Palmer, Whitehead, \& Schuster, 1982).

The colonic responses in patients with IBS appear to be of similar quality to the responses of narmals; however, the quantity of the responses appears greater for IBS patients. There are several different explanations for this quantitative difference. Almy (1951) believed that the colonic contractions were normal responses to emotional arousal and concluded that people with IBS are more neurotic and therefore emotionally aroused more of the time. Latimer (1981) suggested that IBS patients were more pathological and therefore had a propensity to report many symptoms or to mislabel symptoms. In the study by Chasen et al. (1982) the colonic motility of IBS patients differed from normals in response to inflation of an air balloon in the colon. Based on these results, Whitehead and Schuster (1985) concluded that IBS patients are hyperreactive to many stimuli, including stimuli of no psychological significance, such as air balloons, and are, therefore, biologically predisposed to IBS symptoms. 
The limited data available on physiological characteristics of children with RAP are similar to those of IBS. Kopel et al. (1967) studied the motility of the distal colon in 18 children with RAP, 18 normal children, and 10 children with ulcerative colitis under baseline conditions and in response to neostigmine (parasympatho-mimetic) stimulation. The groups did not significantly differ in baseline, however, following injection. RAP children had significantly increased activity and larger contractions than controls.

The result of this increased distal bowel activity is to hinder the movement of gas and stool through the bowel which can cause constipation and distention of the bowel. The stimulation of the stretch receptors in the bowel wall and the high amplitude contractions in children with RAP is a potential explanatory mechanism for the abdominal pain symptoms (Whitehead \& Schuster, 1985).

Adults with irritable bowel syndrome have also been shown to have abnormal intestinal transit times and evidence of colonic spasm (Harvey, Pomare, \& Heaton, 1973). There has been some evidence that these qualities exist in many children with RAP. Dimson (1971) found that $22 x$ (66 of 306) of children with RAP had rectal constipation and that $91 \%$ of these children had delayed transit time. Rectal constipation has been shown to produce abdominal pain (see Dimson, 1971). 
The remaining RAP children (78x) had signs of colonic spasm, with $44 x$ having delayed transit times and $45 x$ having tender colons. In a comparison group of children with migraines without abdominal pain, transit time was delayed in only $27 x$ of the children. The author speculates that the site of delayed transit is most likely to be either the colon or the rectum, and that rectal constipation or colonic spasm mar account for many cases of children with RAP.

Additional indirect evidence for the role of delared transit times and colonic spasm comes from a randomized double-blind, placebo-controlled study testing the effects of a fiber diet in 52 children with RAP (Feldman, McCrath, Hodgson, Ritter, and Shipman, 1985\}. Fifty percent of the experimental (fiber) group showed at least a 50 r reduction in pain attacks in response to an increase of 10 grams of dietary fiber as compared to only $36 x$ of the placebo group. The authors speculated that the mechanism of action is due to the effect of fiber decreasing bowel transit time. Further research is needed to more directly identify the mechanism of action of fiber and to identifying which children will respond to increased fiber diets.

\section{Psychological}

In the absence of organic causes, a psychogenic basis has of ten been assumed to be the cause of RAP. However, a determination of psychogeneity should not be made by 
exclusion, rather, it first must be demonstrated that psychological factors co-occur wilh RAP. In a nonsystematic comparison based primarily on clinical impression rather than objective measures. Apley (1975) reported that children with RAP were more high strung, fussy, excitable, anxious, socially unskilled, or apprehensive, as compared to controls. However, properly controlled studies using more objective, reliable, and valid measures are needed to determine psychological factors associated with RAP. The following discussion will focus on depression, anxiety, and life events in children with RAP since most of the well controlled, objectively assessed studies have examined these variables.

McGrath and his colleagues 119831 compared 30 clinicreferred children with RAP and 30 pain free controls using a structured interview with children and parents, the Birleson self-report depression scale, the Poznanski depression scale rated by the interviewer, and a measure of life stress experienced by the child. The groups did not differ on any of the measures, however, there was a consistent, nonsignificant trend toward more depression in the RAP group.

Rarmer, Weininger, and Hamilton (1984) compared 44 children with abdominal pain of organic origin lCrohn's disease, 24; ulcerative colitis, 20), 16 children with abdominal pain with no detectabie organic pathologr, and 30 
pain-free controls on 12 variables related to personal. family, and social adjustment. Results showed that the organic and non-organic groups did not differ on depression scores (Childrens' Depression Inventory), however, both groups showed higher scores than the control group. No differences were found between groups in stressful life events (Heisel life event scores). The frequency of severe psychological distress, as indicated by more than two standard deviations outside the control group mean, was higher among children with abdominal pain than controls. Severe depression occurred in $13 x$ to $20 x$ of the abdominal pain group as compared to three percent in controls.

Hodges and her colleagues (Hodges et al., 1984; Hodges et al., 1985a; Hodges et al., 1985b) conducted three studies to evaluate depression, anxiety, and life events in children with RAP and their families. One study compared 25 clinic referred children with RAP with 67 behaviorally disordered (BD) children and 42 healthy controls on the Childrens' Depression Inventory and the Child Assessment Schedule (CAS), a structured interview. On both measures, the RAP children did not differ from the control children and both groups were significantly lower than the BD children. The other two studies compared 30 RAP children with the same two controls (BD and healthy) on the State-Trait Anxiety Inventory for Children (STAI-C), the CAS, and Coddington 
Life Events Inventory. Results showed that the RAP and $B D$ groups had similar anxiety scores on the STAIC and the CAS and that both were significantly higher than the healthy controls. It was also noted that a number of RAP childrer had no substantial anxiety. Both RAP and $B D$ children reported significantly more life events and life change units (index of stress) than the healthy children. The life change units for the RAP and $B D$ were between one and two standard deviations above the mean for 10 year olds.

To summarize, studies utilizing appropriate controls and objective measures showed that depression consistently was not associated with RAP. In the one study that did show a relationship, depression did not distinguish organic from non-organic abdominal pain (Raymer et al, 1984). Studies evaluating life events in RAP children were inconsistent with two studies indicating no significant difference between RAP and control children, and one study showing a significant difference. In the one study that evaluated levels of anxiety (Hodges et al, 1985b), RAP children were shown to be significantly more anxious than controls on two separate measures of anxiety, however, not all children with RAP appear to have increased levels of anxiety.

Interestingly, when psychological distress is found to be associated with RAP children, it does not appear to be unique to them, that is. the comparison groups (behaviorally 
disordered or abdominal pain with an organic basisl also share this distress. This finding suggests that other variables may be operative in the development and maintenance of RAP symptoms. It could be that psychological variables and RAP symptomatology are both mediated by other ret to be identified variables. The inconsistencr in psychological findings also suggest that the cause of RAP is multifactorial and that these variables may interact with other variables to produce symptoms.

Apley (1975) suggested criteria to justify labeling the cause of RAP as psychogenic: 1) there should be negative evidence against organic disease; 21 there should be positive evidence of an emotional disturbance; and 3) relief should be seen with amelioration of the emotional disturbance. However, it should be noted that there is a subgroup of children with RAP for which there is no evidence for elther organicity or psychogeneity. In addressing this issue, Barr and Feuerstein (1983) questioned the following two traditional clinical assumptions regarding RAP: "1) that the cause of the syndrome must be either organic or psychogenic, and 2) that the presence of the symptom indicates the presence of disease, whether organic or psychogenic" (p. 24). They proposed that a pain episodes in some children with RAP may be due to some nonpathologic mechanism. They argue that the lack of appropriate 
diagnostic tools for identifying possible mechanisms in RAP may result in unwarranted attributions of psychogeneity.

They suggested an alternative clinical model which includes a "dysfunctional" RAP syndrome. This dysfunctional category would include normal children with pain episodes that occur for normal reasons. As in the case of lactose intolerance, pain episodes may well be the "result of a normal constitutional factor llow levels of small intestine lactose activity during school age) and a normal environmental factor (ingestion of lactose\}." (pp. 23-24) In Apley's surveys (1975), 51\% of the unselected sample and at least 14\% of the hospital referred sample lacked positive evidence for organic or psychogenic factors in RAP. He recommended that the grouping include an organic group, a stress group, and "provisional" group. The inclusion of this dysfunctional or provisional category suggests that for a subgroup of children with RAP, some yet to be identified pathologic or nonpathologic mechanism may be operative.

\section{Family}

Although the presence of psychological distress in children of RAP is inconsistent, the evidence of psychological distress in the families of RAP children is more consistent. In two studies by Hodges et al. 11985a; 1985b), RAP mothers scored significantly higher on measures of anxiety and depression than did the mothers of healthy 
controls, although they were equal to mothers of behaviorally disturbed (BD) children. Normatively, $39 x$ of the RAP mothers scored greater than or equal to one standard deviation above the mean for anxiety on the State-Trait Anxiety Inventory (STAI), and $25 x$ scored in clinically depressed range on the BDI. Fathers of RAP children scored significantly higher on the STAI than healthr or BD fathers; 25x of the fathers scored greater than or equal to one standard deviation above the mean.

Routh and Ernst (1984) interviewed the mothers of 20 children with abdominal pain from a known organic pathology and 20 nonorganic RAP children to assess psychological disturbance of first and second degree relatives. A significantly higher proportion of RAP children had relatives with either alcoholism, antisocial or conduct disorder, attention deficit disorder, or somatization disorder as compared to the organic pain children. In particular, 50x of the RAP children had one or more relatives with somatization disorder, as compared to five percent of the organic pain group. The two groups also differed on the somatic complaints scale of the Child Behavior Checklist, with the RAP group showing higher scores than the organic group. The authors concluded that abdominal pain in childhood may be a hysterical symptom and a precursor of somatization disorder in adulthood. Although 
their study did not address the mechanism underlying the association between RAP and the incidence of somatization disorder in relatives, they suggested a genetic predisposition to hysteria or a social learning hypothesis.

Several studies have noted that pain problems tend to run in families. Oster (1972) suggested that frequent manifestations of pain in parents and families may be a precipitating factor in the development of pain symptoms in children. Table 5 shows the incidence of family pain problems across a number of studies. Apley (1975) reported that the parents and siblings of children with RAP had an incidence of abdominal complaints that was nearly six tumes higher than that of controls. It seems clear from these studies that abdominal pain, as well as other pain problems. are more prevalent in the families of children with RAP than in no pain controls.

Given the prevalence of other pain symptoms in the families of RAP children, it could be speculated that it is not the specific bodily location of pain which shows a familial tendency, but rather, the pain proneness. This is shown in Oster's (1972) report of a higher prevalence of headache than abdominal pain in the parents of 20 children who had abdominal pain only for three or more consecutive years. However, given this observed tendency, it is impossible to distinguish between the role of modeling and 
Table 5

Percentage of Family Members with Pain Complaints

\begin{tabular}{|c|c|c|c|c|c|c|}
\hline \multirow[b]{2}{*}{ Study } & \multicolumn{3}{|c|}{ Children with RAP } & Children & without & \multirow{2}{*}{$\frac{\operatorname{RAP}}{\operatorname{mi} \mid y}$} \\
\hline & Mother & Father & Family & Mother & Father & \\
\hline $\begin{array}{l}\text { Apley } \\
\text { (1975; } N=420 \text { ) } \\
\text { abdominal pain } \\
\text { headaches } \\
\text { peptic ulcer } \\
\text { appendicectomy }\end{array}$ & $\begin{array}{l}17 \\
-- \\
-- \\
--\end{array}$ & $\begin{array}{l}11 \\
-- \\
--\end{array}$ & $\begin{array}{l}46 \\
14 \\
10 \\
8\end{array}$ & $\begin{array}{l}2 \\
-- \\
--\end{array}$ & $\begin{array}{l}2 \\
-- \\
--\end{array}$ & $\begin{array}{l}8 \\
3 \\
3 \\
3\end{array}$ \\
\hline $\begin{array}{l}\text { Oster ac } \\
\text { (1972; N=636) } \\
\text { abdominal pain } \\
\text { headaches }\end{array}$ & $\begin{array}{l}21 \\
50\end{array}$ & $\begin{array}{l}17 \\
28\end{array}$ & -- & $\begin{array}{l}10 \\
26\end{array}$ & $\begin{array}{r}6 \\
14\end{array}$ & -- \\
\hline $\begin{array}{l}\text { Osterd } \\
(1972 ; \quad n=20) \\
\text { abdominal pain } \\
\text { headaches }\end{array}$ & $\begin{array}{r}0 \\
44\end{array}$ & $\begin{array}{r}8 \\
23\end{array}$ & -- & -- & -- & -- \\
\hline $\begin{array}{l}\text { Stone \& Barberob } \\
\text { (1970) ( } n=102 \text { ] } \\
\text { abdominal pain } \\
\text { headaches }\end{array}$ & $\begin{array}{l}50 \\
10\end{array}$ & $\begin{array}{l}46 \\
--\end{array}$ & -- & -- & -- & -- \\
\hline $\begin{array}{l}\text { Christensen \& } \\
\text { Mortensenb } \\
(1975 ; n=34) \\
\text { abdominal pain }\end{array}$ & -- & -- & 28 & -- & -- & 7 \\
\hline
\end{tabular}
a nonselect sample
b clinic referred sample
c sample includes abdominal pain and headaches
d abdominal pain only for three consecutive years 
some biological predisposition (MoGrath and Feldman, 1986; Oster, 1972J.

Christensen and Mortensen (1975) provide some support for the notion that abdominal pain is transferred through modeling rather than biological means. In their follow-up, they found that the children of adults who had RAP in childhood were no more likely to have RAP than were controls. However, it was found that children who had parents who were currently experiencing abdominal pain were more likely to have abdominal pain themselves than children with parents who were not experiencing abdominal pain currently. This finding suggests that it is the occurrence of current symptoms that is a significant factor in childhood abdominal pains rather than parental history of RAP.

\section{Learning}

\section{Operant}

From an operant model, illness behavior and/or abnormal physiological responses may be reinforced by the responding of parents or others to a child's somatic complaints or by the avoidance of responsibility (Whitehead, Winget, Fedoravicus, Hooley, \& Blackwell, 1982; Miller, 1977). Experimental evidence supporting an operant model of RAP comes from two single case designs. Sank and Biglan (1974) treated a 10 year-old boy with a two and a half year history 
of RAP through a token system. Reinforcement was provided for absence of severe attacks, pain ratings below a criterion, and school attendance. In addition, attention and privileges for being ill were reduced. The program was successful in reducing pain related behaviors and increasing school attendance. Miller and Kratochwill (1979) utilized a time-out procedure at home and at school in the treatment of a 10 year old girl with a one year history of RAP. In this study, pain complaints were followed by time-out consisting of removing the girl from adult attention and any activities. The program rapidly reduced complaints to zero and was maintained at one-year follow-up. These two studies provide indirect support for the operant model of RAP, however, reducing the pain complaints of children with RAP does not mean that the experience of pain has been reduced (McCrath, 1986).

Additional indirect evidence in support of the operant model of RAP comes from a retrospective study showing an association between reinforcement for somatic complaints in childhood and adult irritable bowel syndrome (Whitehead et al., 1982). However, this study is 1 imited by its retrospective methodology. More objective, direct evidence of the process by which RAP symptoms become conditioned is needed to support the operant model. 
Modeling

Evidence for the role of modeling in the development and maintenance of RAP is provided by the increased prevalence rates of abdominal pain and other pain symptoms in the parents and families of children with RAP. Although it is difficult to disentangle the effects of genetics and modeling, the data provided by Christensen and Mortensen (1975) implicates the role of modeling (see details above). Osborne, Hatcher \& Richtsmeler (1989) recently examıned the role of social modeling in 20 children with recurrent unexplained pain (abdomen or chest) and 20 children with recurrent pain secondary to sickle cell anemia. They defined a model as someone known who had a pain-related disorder or engaged in pain or illness behavior regularly. Both children and parents in the unexplained group identified a model significantly more often than children and parents in the explained pain group. In addition, the children and parents in the unexplained pain group were more likely to report positive consequences for their pain than the explained pain group, Indicating that they were more likely to recelve positive reinforcement for their pain complaints.

\section{Behavioral}

Latimer (1981) critically reviewed current models for explaining irritable bowel syndrome (IBS), which is thought to be the adult counterpart to RAP (Whitehead \& Schuster, 
1985j. In this paper he reviewed the digestive disease model, which posits that the primary problem is in the GI tract and that any psychological problems are secondary; the psychiatric disease model which assumes that the primary problem is a psychiatric illness and that any GI problems are secondary; and the psychophysiological model which assumes that IBS symptoms are the result of physiological changes that normally accompany certain emotional states, only more sustained or intense. Latimer expressed the inadequacy of these models to explain the complex clinical features of IBS and proposed a behavioral model. Although this model was proposed for IBS, the issues raised appear relevant for the development and maintenance of abdominal symptoms in children.

Latimer's behavioral model has three central features. First, behavior at the verbal, motoric, and physiological levels are capable of independence or dysynchrony. Second. that these aspects of behavior are dimensional or quantitative variations of normal, as opposed to categorical. Third, that there is a genetic predisposition to neuroticism which predisposes which to IBS. This model suggests that IBS is a behavioral problem. Maladaptive behavior may consist of what the person says, what he does, and how he responds physiologically to certain events, or any combination of these. Latimer reviewed some animal 
research which suggests that maladaptive physiological responses and IBS symptoms are a result of unlearned responses to stressful circumstances in neurotic individuals. To explain why all neurotics do not suffer from IBS, he proposes that people with IBS differ in their verbal and overt behavior as a result of idiosyncratic learning experiences. He goes on to say that these learning experiences may occur in childhood. For example, a child may vicariously learn misconceptions about "normal" bowel habits. Similarly, a child may have never learned to discriminate the various visceral sensations, such as hunger, constipation, anxiety, and colonic contractions, and mar interpret them all as stomach pain.

This behavioral model has some implications for research. The notion of dysynchrony at the three levels of behavior suggests that people suffering for IBS are not a homogeneous group and that measurement needs to be made at these three levels in order for comparisons to be made across research samples. Many of the other components of this model have yet to be systematically investigated.

\section{Issues of Continuity/Discontinuity}

The adult counterpart to RAP in childhood is thought by some to be irritable bowel syndrome (Whitehead \& Schuster. 1985). The diagnostic criteria for IBS are similar to RAP: 1) abdominal pain; 2) change in bowel habit (diarthea or 
constipation); and 3 ) absence of organic abnormalities (Schuster, 1983). In addition, the similar findings of Harvey et al. (1973) and Dimson (1971) regarding abnormal intestinal transit times and evidence of colonic spasm suggests continuity between these physiological aspects of RAP and IBS. However, additional research needs to further validate these findings.

Other data to consider regarding the continuity of RAP from childhood to adulthood is the long-term follow-up studies. As discussed earlier in the present paper, about one-third to one-half of children with RAP experience recurrent abdominal pain symptoms in adulthood. In the longest follow-up study to date (28-30 years). Christensen and Mortensen (1975) reported that greater than one-half (18) of the 34 adults who had RAP in childhood reported current abdominal symptoms, as compared to about one-quarter 113 of 45$)$ of the controls. It was also reported in this study that 11 of the 18 persons with continual abdominal symptoms reported having a symptom-free period during adolescence. This is an interesting finding which makes the issue of continuity all the more confusing

The long-term follow-up data also show that as many as two-thirds of adults with a history of RAP have some pain symptoms, as compared to $20 x$ to $30 x$ for controls. These long-term data argue more for the continuity of somatic 
symptoms in general rather than specific localized disorders. It could be that individual or environmental characteristics, or some combination these, predispose a person toward somatic disorders or complaints in general.

To summarize, it appears that for a subgroup of children, RAP symptoms are maintained into adulthood and manifest themselves in abdominal pain or IBS symptoms. For an even larger subgroup of people, childhood somatic disorders and complaints in general appear to be continued into adulthood; and for another subgroup of people with RAP in childhood, symptoms appear to be transient. The challenge to researchers is to identify the individual and/or environmental variables which are causal in the development and maintenance of chronic pain syndromes such as RAP.

Treatment Studies of RAP

Treatment of children with RAP has traditionally consisted of reassurance that there is no serlous disease present and explanation of the effects of emotional arousal on symptoms. Two studies provide some evidence for the effectiveness of such a treatment. Apley and Hale (1973) compared the long-term follow-up of 30 children with RAP who were treated with reassurance and explanation with a previous follow-up sample of 30 untreated RAP children. The outcome of the treated sample was similar to the untreated sample. However, of those children who responded to 
treatment, the symptoms of the trested group responded much more rapidly than did the untreated group. In an uncontrolled study, Christensen and Mortensen (1975) followed-up 34 children with RAP who were treated with reassurance and explanation 30 rears earlier. Their results suggested that about half the children with RAP, treated with reassurance and explanation, will suffer from abdominal symptoms as adults. Although these studies are suggestive of the type of outcome to be expected from reassurance and explanation, there are no well controlled prospective studies evaluating this treatment.

The two single-case design studies reviewed earlier Miller \& Kratochwill, 1979; Sank \& Blglan, 1974) provided some evidence of the effectiveness of operant techniques in the treatment of RAP. What remains unclear about these two studies is whether the subjective experience of pain has been reduced or just the verbal complaints. Teaching the child not to report pain complaints may not be in the child's best interest (Mcorath, 1986).

A recent controlled group study evaluated the effectiveness of multicomponent cognitive-behavioral treatment for eight children with RAP (Sanders, Rebgetz, Morrison, Bor, Cordon, Dadds \& Shepard, 19891. Treatment components included behavioral techniques Iself-monitoring, positive reinforcement of for pain reports below a certain 
criterion, with the criterion revised weeklyl and cognitive coping strategies (relaxation, coping self-statements, refocusing attention away from pain. self-reinforcement, and imageryl. Children with constipation were excluded from the study. Results showed that both the experimental and control groups improved on child and parental dally pain reports; however, the experimental group responded more quickly. showed a higher incidence of complete elimination of pain reports, and showed a significantly greater reduction in teacher observed pain behaviors at follow-up. This study represents the first controlled group study to evaluate a psychological treatment of RAP in children.

Although the results from Sander et al. (1989) provide partial support for the effectiveness of a cognitivebehavioral approach to treatment of RAP, there are some methodological considerations which limit their interpretation. First, despite random assignment, there were pretreatment differences in the amount of pain reported by the children. The authors also reported large within-subject variability suggesting that the sample was heterogeneous. Secondly, using a multicomponent treatment package makes it impossible to determine the relative effectiveness of the individual treatment components. Thirdly, as in the two single-case studies reviewed above, by reinforcing children for reductions in pain reports, it remains unelear whether 
the subjective experience of pain has been reduced or just the verbal complaints. Teaching children to underreport pain raises some important ethical questions. Finally, as reviewed earlier, several mechanisms have been proposed to account for the development and maintenance of RAP symptoms. The design of this study does not allow for the determination of which subject characteristics or symptom presentations were responsive to which treatment components.

The studies reviewed above demonstrate that multiple behavioral and cognitive-behavioral treatment procedures are at least partially effective in reducing pain behavior and self-reports of pain in children with RAP. However, given the apparent heterogeneity of children with RAP as a group, treatment outcome studies need to be designed to highlight the different mechanisms operating to maintain RAP symptoms and the individual physiological and behavioral characteristics which are associated with improved treatment outcome. In support of this notion, a recent clinical replication series by Finney, Lemanek, Cataldo, Katz and Fuqua (1989) evaluated the effect of targeting treatment components to specific symptom presentations in 16 children with RAP. Treatment procedures included self-monitoring. limited parental attention, relaxation training, increased dietary fiber, and required school attendance. Individual subjects received a tallored treatment package that was 
based on behavioral concerns and individual symptom presentations identified during assessment. Treatments were brief, averaging 2.5 sessions with additional phone contacts. Global parental and therapist outcome ratings of pain showed that $81 x$ (13) of the children were improved or resolved. Other functional measures of pain, such as school absence and medical care utilization, also decreased significantly following treatment. This study represents the first attempt to evaluate the effectiveness of talloring components of treatment packages to specific presenting symptoms. However, the case study approach makes it difficult to adequately evaluate the effectiveness of the treatment programs and the use of multiple treatment components makes it impossible to establish the contribution of individual treatment components. Studies utilizing adequate control and a design that allows for the evaluation of specific treatment components are needed.

Given the apparent heterogeneity of children with RAP as a group and the paucity of treatment outcome data to guide treatment selection. more well-controlled treatment outcome studies are needed. Studies should be designed to highlight which individual physiological and behavioral symptoms are effected by which treatment procedure. Such studies could provide indirect evidence of the different mechanisms operating to maintain RAP symptoms. 


\section{INTRODUCTION}

Recurrent abdominal pain (RAP) is a functional gastrointestinal disorder typically defined as a syndrome in children three years of age or more who had at least three episodes of abdominal pain, severe enough to affect their activities, over a period longer than three months, without a known organic cause. RAP is the most common pediatric gastrointestinal disorder (Whitehead, 1986). Epldemiologic information indicates that as many as $30 x$ of school-aged children will report stomach pains at some time through theit school years and as many as $10 x$ to $15 x$ of children suffer from recurrent stomachaches at any given point in time Aapler \& Naish, 1958; Oster, 1972). The recurring nature of the disorder can result in increased school absence, medical care utilization, and family disruption (Finney et al., 1989; Fowler et al., 1985)

Treatment of children with RAP has traditionally consisted of reassurance that there is no serious disease present and explanation of the effects of emotional arousal on srmptoms: however, there are no controlled prospective studies evaluating this treatment. Two studies using singlecase designs provided some evidence of the effectlveness of operant techniques in the treatment of RAP. Sank and Biglan (1974) used a token system in which reinforcement was provided for absence of severe attacks, pain ratings below a 
criterion, and school attendance. The program was successful in reducing pain related behaviors and increasing school attendance. Miller and Kratochwill (1979) utilized a timeout procedure at home and at school in which pain complaints were followed by time-out consisting of removing the subject from adult attention and any activities. The program rapidly reduced complaints to zero and was maintained at a one-rear follow-up. These two studies provide indirect support for the operant model of RAP. However, a potential problem with these techniques is their targeting of pain reports; shaping the child to not report pain symptoms does not mean that the child's experience of pain has been reduced (McGrath, 1986). It also raises an important ethical issue in that teaching children to suppress reports of pain may not be in their best interest.

In the first controlled group study to evaluate the effectiveness of a psychological treatment for RAP, Sanders et al. (1989) compared a multicomponent cognitive-behavioral treatment for eight children with RAP with a waiting-list control group. Subjects displaying symptoms of constipation were excluded from the study. Treatment components included behávioral techniques (self-monitoring, positive reinforcement of pain reports below a certain criterion, with the criterion revised weekly) and cognitive coping strategies (relaxation, coping self-statements, refocusing 
attention away from pain, self-reinforcement, and imageryl. Results showed that both the experimental and control groups 1 mproved on child and parental daily pain reports; however, the experimental group responded more quickly, showed a higher incidence of complete elimination of pain reports. and showed a significantly greater reduction in teacher observed pain behaviors at follow-up. Although these results provide partial support for the effectiveness of a cognitive-behavioral approach to treatment of RAP, the use of a multicomponent treatment package makes it impossible to determine the relative effectiveness of the individual treatment components nor does it allow for the determination of which subject characteristics or symptom presentations were responsive to which treatment components.

A diet-based approach to treatment has been shown to be successful in a percentage of children with RAP. In a randomized double-blind, placebo-controlled study of 52 children with RAP, Feldman and his colleagues (1985) demonstrated the effectiveness of a high fiber treatment; 50x of the experimental (fiber) group showed at least a $50 \%$ reduction in pain attacks in response to an increase of 10 grams of dietary fiber as compared to only $36 x$ of the placebo group. The authors speculated that the mechanism of action of the fiber is the decrease in bowel transit time. Delared transit time is thought to be the result of abnormal 
motility of the distal colon. Increased bowel activity can hinder the movement of gas and stool through the bowel which can cause constipation and distention of the bowel. The stimulation of the stretch receptors in the bowel wall and the high amplitude contractions of the smooth muscles are thought to cause the abdominal pain sensations (Whitehead \& Schuster, 1985). The effects of increased fiber in the diet of children with RAP provide indirect evidence in support of this model and suggests that there is a subgroup of children diagnosed with RAP in which abnormal colonic motility may be an etiological and maintaining factor.

Based on the assumption that children diagnosed with RAP are a heterogeneous group and that different mechanisms may be operating within different subgroups of children with RAP, a recent clinical replication series evaluated the effectiveness of tailoring components of a treatment package to specific presenting symptoms. Finney and his colleagues (1989) evaluated the effect of largeting treatment components to specific symptom presentations in 16 children with RAP. Treatment procedures included self-monitoring, limited parental attention, relaxation training, Increased dietary fiber, and required school at tendance. Individual subjects recelved a tallored treatment package that was based on behavioral concerns and individual symptom presentations identified during assessment. Treatments were 
brief, with from two to six clinic appointments and additional phone contacts. Global parental and therapist outcome ratings of pain showed that $81 \%$ (13) of the children were improved or resolved. Other functional measures of pain, such as school absence and medical care utilization. also decreased significantly following treatment. However, the case study approach used in this study makes it difficult to adequately evaluate the effectiveness of the treatment programs and the use of multiple treatment components makes it impossible to establish the contribution of individual treatment components. Studies utilizing adequate control and a design that allows for the evaiuation of specific treatment components are needed.

The initial successes of these studies suggest that both phrsical (increasing dietary fiber) and psychological treatments of RAP, specifically behavioral and cognitivebehavioral treatments, show some promise. However, more controlled studies designed to highlight which individual physiological and behavioral symptoms are effected by which treatment procedure are needed. Such studies could provide indirect evidence of the different mechanisms operating to maintain RAP symptoms.

\section{Proposal}

The present study proposed that symptom presentation may provide a basis for treatment selection. The purpose of 
the present study was to provide treatment outcome data for etiologically-based subgroups of children with RAP using single-case methodology and to provide indirect evidence of possible mechanisms of RAP in children. In reviewing the existing treatment outcome studies, two etiological models of RAP hold promise and may be indicative of specific treatment treatment approaches: constipation as a result of abnormal colonic motility and operant learning. The present study used treatments derived from these two models.

Children with episodic pain with and withoul constipation will receive treatment. The constipation intervention was designed to speed up bowel transit tlmes and to regulate bowel movements in children with constipation symptoms. The treatment consisted of a high fiber diet. The operant learning intervention was designed for children without constipation symptoms. This treatment was designed ta structure the parent-child interaction toward one of coping with pain symptoms, thereby, changing the contingencies that may be maintaining the symptoms. This treatment consisted of two components: 1 l teaching children relaxation skills as a coping response and, 2) teaching parents to respond to their child's pain complaints with encouragement to cope with the pain through the use of the relaxation procedure.

The hypothesis that presenting symptoms are indicative of a specific treatment approach was tested by providing 
treatments from both proposed models to those children with RAP with and without symptoms of constipation. Support for this hypothesis would come from observing no change in pain symptoms following presentation of the treatment that was not suggested by the proposed model (nonsuggested treatment) and observing a change in pain symptoms following presentation of the treatment suggested by the proposed model (suggested treatment).

Hypotheses Related to Subject Characteristics

1) As a group, subjects will show increased levels of depression and anxiety as measured by the Children's Depression Inventory (Kovacs, 1978) and the State-Trait Anxiety Inventory-Children (Spielberger, 1973) relative to age-appropriate norm groups.

2) As a group, subjects will score outside the normal range on the depression, somatic complaints, and internalizing scales of the Child Behavior Checklist (Achenbach \& Edelbrock, 1979).

3) As a group, mother's of the subjects will show increased levels of depression as measured by the Beck Depression Inventory (Beck, Ward, Mendelson, Mock, \& Erbaugh, 1961), relative to normal adult norms. Hypotheses Related to the Interventions

1) Subjects will show no reductions in self-reported and mother-reported stomach pain frequency, intensity, and 
duration as compared to baseline levels following the introduction of a treatment not suggested by the presenting symptoms (1.e., constipated subjects: relaxation training and parent instruction; nonconstipated subjects: diet and bowel habit training).

2) Subjects will show reductions in self-reported and mother-reported stomach pain frequency, intensity, and duration as compared to baseline levels following the introduction of a treatment suggested by the presenting symptoms li.e., constipated subjects: diet and bowel habit training; nonconstipated subjects: relaxation training and parent instruction).

3) Subjects will show no reductions in the functional indicators of pain as compared to baseline levels following the introduction of the nonsuggested treatment.

4) Subjects will show reductions in the functional indicators of pain as compared to baseline levels following the introduction of the suggested treatment. 
METHOD

Subjects

Children between 6 and 12 rears of age who were suffering from recurrent abdominal pain were recruited from referrals by local physicians and self-referrals from local media announcements. Following an initial telephone screening procedure, the children and one of their parents were invited to come into the clinic for structured interviews to assess the child's history of stomachaches. confirm diagnostic criteria for recurrent abdominal pain. and assess signs of possible organic cause for the pain. All children had been under the care of a pediatrician or family phrsician prior to entering the research program and each phrsician completed a written evaluation of their patient. Subjects who met selection criteria and agreed to participate were included in the study. All subjects fulfilled Apler's (1975) research criteria for recurrent abdominal pain: (a) that the child have at least 3 episodes of pain over a period longer than 3 months; (b) that the pain be paroxysmal in nature; (c) that the pain be severe enough to affect their activities (e.g. recreational, school, relationships); and (d) that there be no known organic cause.

Eighteen children were initially interviewed. Or these, 12 completed treatment, one dropped out of treatment for 
personal reasons, one was excluded from the study due to noncompliance with the research protocol, three elected to drop out before treatment, and one spontaneously improved during baseline. Three of the 18 subjects (C1, C2, OP9) were recruited and treated as pilot subjects. The demographic characteristics of the 13 children who received treatment are 1 isted in Table 6 .

All subjects were assessed for symptoms of constipation. The determination of whether a child was constipated was based upon frequency and consistency of bowel movements as reported on the Stomachache History interviews or by baseline dally monitoring data. Constipation criteria included at least one of the following: 1 ) self-report or self-monitoring record of hard or "pellet-like" stools, 2) self-report by child or parent of difficulty or straining during bowel movement attempts, or 3) bowel movements frequency no more of ten than once every three days. Four subjects met criteria for constipation. Table 7 and 8 shows bowel activity data used to assess constipation criteria.

\section{Measurement}

Before treatment and concurrently with baseline data collection, children and their mothers completed psychological questionnaires and structured interviews. 


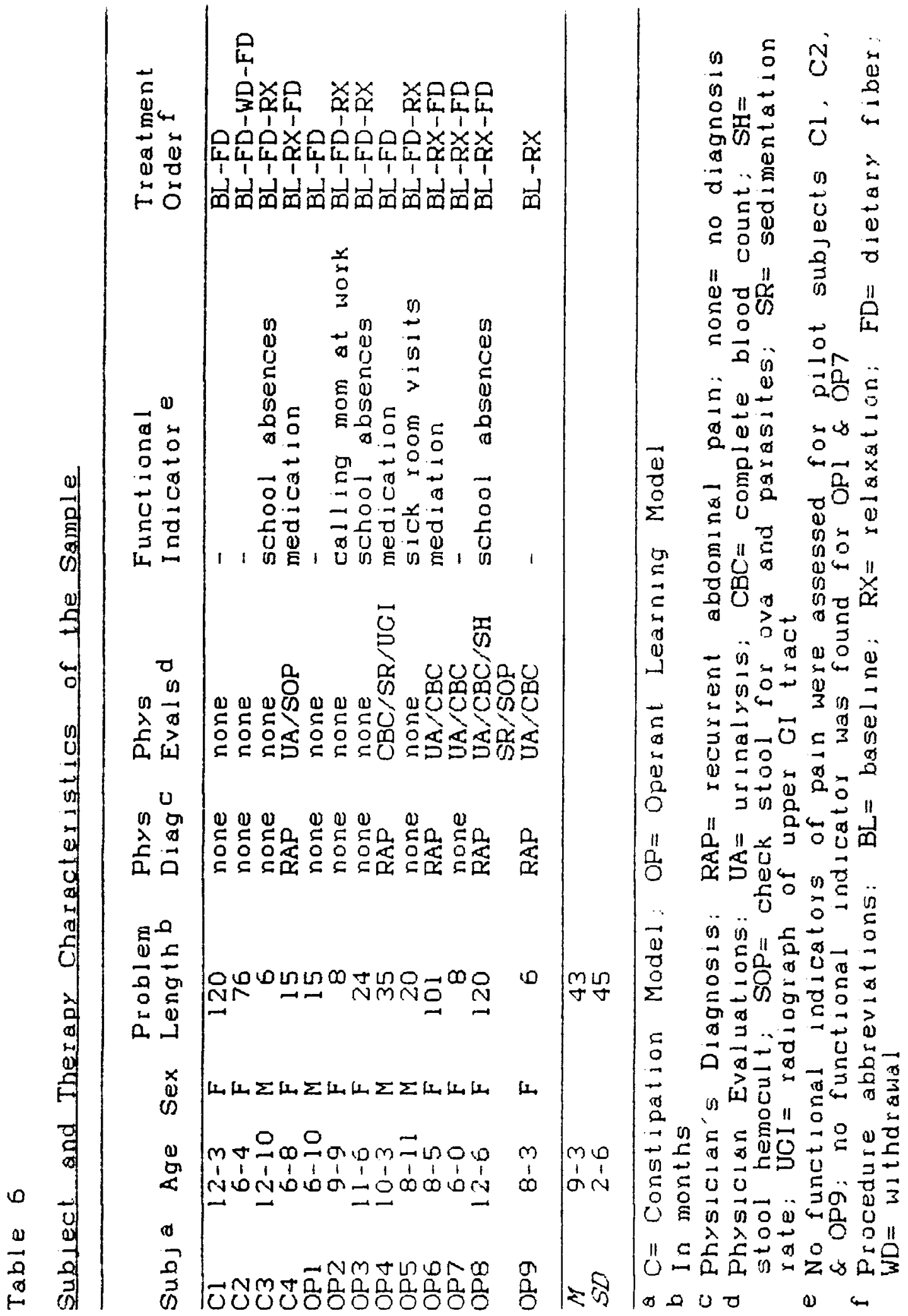




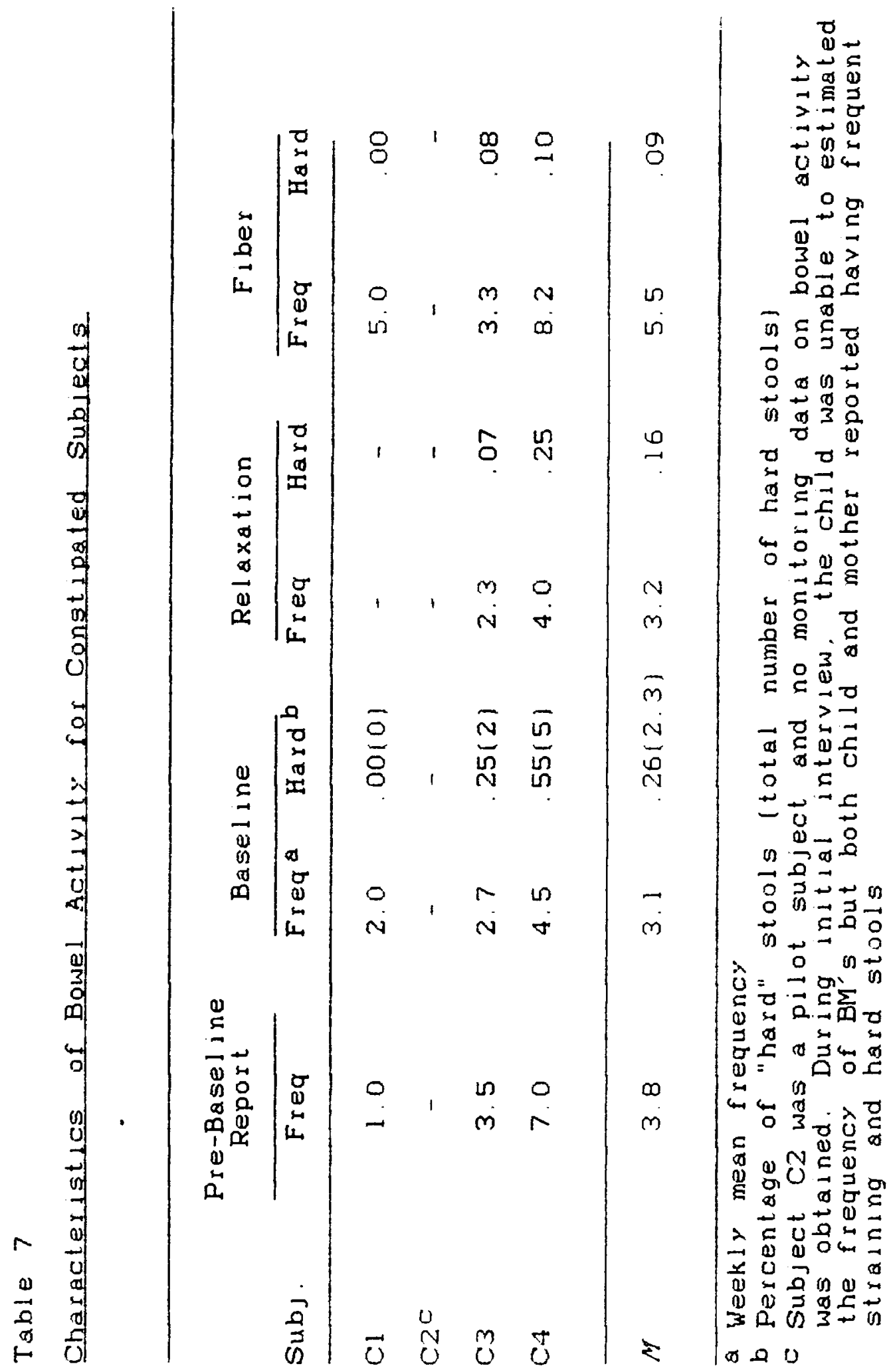




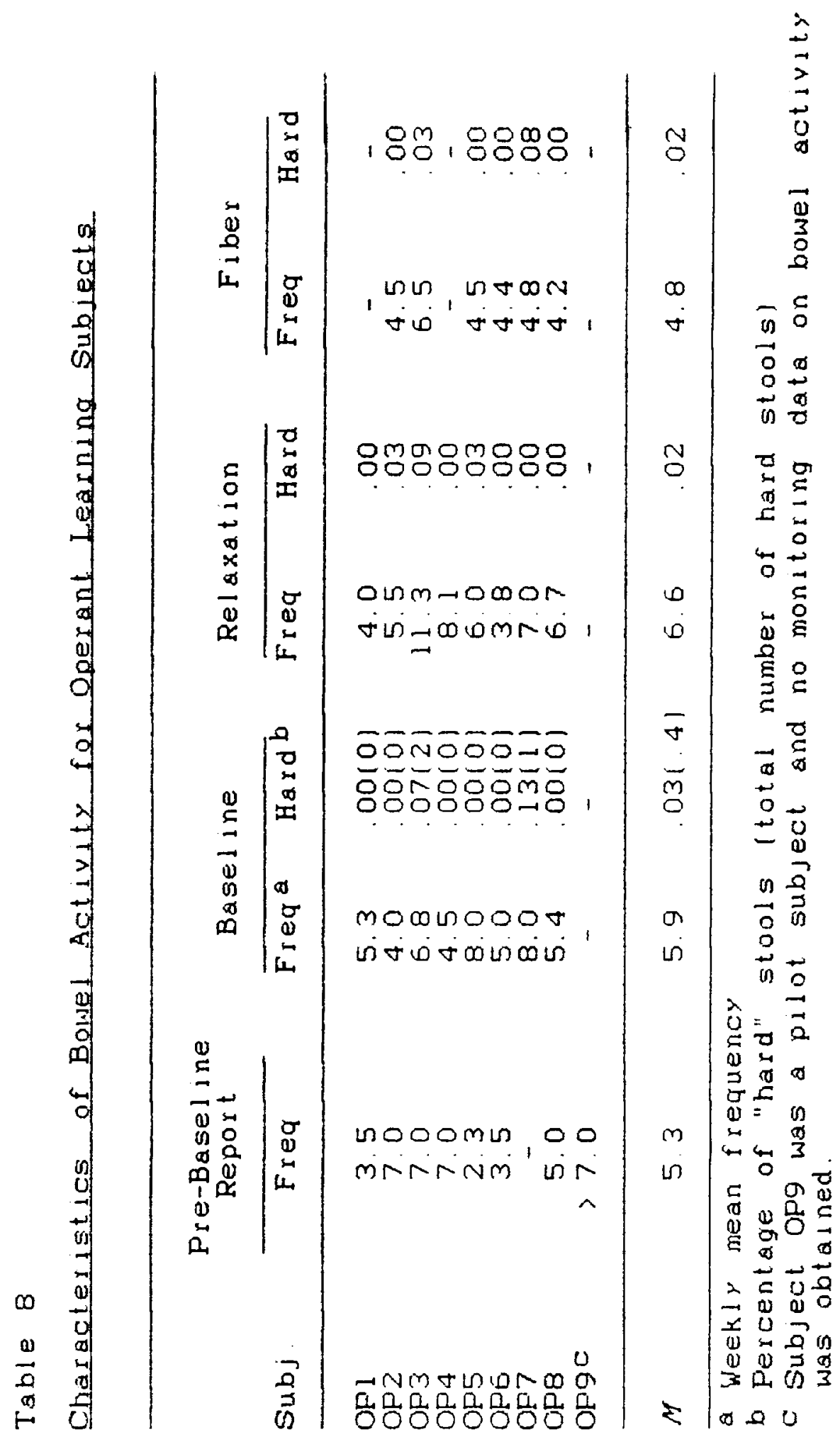


Child self-report. To assess psychological characteristics of the current sample, children of appropriate age (at least 8 years old) completed the Children's Depression Inventory (CDI: Kovacs, 1978) and the State-Trait Anxiety Inventory for Children ISTAI-C: Spielberger, 1973).

To assess symptoms of constipation and the effect of increased dietary $f$ iber on bowel transit time, children monitored the number of bowel movements and the consistency of the stool (i.e., watery, normal, or hard) once per day on daily diary cards (see Appendix A). The consistency categories were operationalized for the subjects and ther mothers as described in Appendix B. Tables 6 and 7 show the child's self-reported frequency of bowel movements per week, the number of "hard" stools monitored during baseline, and the mean number of bowel movements per week during baseline. Child interview. All subjects were given a semistructured interview using the Stomachache History-Child form (see Appendix $C$ ). This interview assessed diagnostic criteria for RAP, characteristies of the stomachaches, constipation, and provided a funetional analysis of the stomachaches.

Parent self-report. Mothers of the children completed the Beck Depression Inventory (Beck, Ward, Mendelson, Mock, 
\& Erbaugh, 1961) and the Child Behavior Checklist (Achenbach \& Edelbrock, 1979\}.

Parent interview. Mothers of the children were given a semi-structured interview using the Stomachache HistoryAdult form (see Appendix D). This form assessed the parent's perception of the characteristics of their child's stomachaches. Similar to the child interview, it assessed diagnostic criteria for RAP, characteristics of the stomachaches, constipation, and provided a functional analysis of the stomachaches.

\section{Dependent Measures}

Three dependent measures were used to assess treatment effects: one self-report measure of pain, one observational measure, and, when possible, one functional indicator of pain.

Self-monitoring. Children were instructed to record stomach pain frequency, intensity, and duration on a daily pain diary. They recorded in their diaries four times daily (breakfast, lunch, dinner, and bedtime; see Appendix A). At each rating period they recorded the intensity and duration of any stomachache that they had since the previous rating period. Intensity was measured using the following fivepoint scale: 0-no stomach pain: l-mild pain: I don't notice the pain if I don't think about it; 2-moderate pain: it hurts but I can do most things; 3-severe pain: it hurts and 
it is hard to pay attention but I can do simpie things: 4very severe pain: it hurts so much that I can't do anything. Children self-monitored on a daily basis throughout baseline and treatment phases and dally for one week at one, three or six month follow-up. The daily pain diary yielded a number of different parameters, three of which are reported here: (a) total weekly stomach pain episodes (1.e., frequency); (b) overall stomachache index score which was calculated by summing the product of intensily and duration for those subjects who were able to provide a reliable indication of duration or by summing the intensity ratings for those subjects who were unable to provide a reliable indication of duration; and (c) number of stomachache-free dars per week.

Parent pain observation. Each mother was instructed to record the frequency, intensity, and duration of her child's behavior that indicated that her child was having stomach pain. The mothers were instructed to record on monitoring sheets each stomach pain episode that occurred during the last 24 hour period (see Appendix E). They were told not to ask the child for the information but to record their own perceptions. For each episode they recorded the intensity of their child's pain using the same five-point scale as the child.

Parents observed their children on a dally basis throughout baseline and treatment phases and dally for one 
week at follow-up. Since parents had difficulty in estimating the duration of their child's stomachaches and because it provided little new information only the total weekly stomach pain episodes observed was reported here.

Functional indicatorg of pein A measure of dieruption of function was determined during baseline and individualized for each subject. Table 6 shows the functional indicators used for each subject. Amount of medication consumed was used for three subjects, number of school absences for three subjects, number of school sick room visits for one subject, and number of calls to mother at work with complaints of pain for one subject. For five of the subjects data were either not obtained lplot subjects C1.C2, \& OP9) or a reliable indicator could not be Identified IOPI \& OP7). School data were obtained from school records and parental monitoring was used to record other functional indicators. Table 9 shows the school attendance data for the subjects

\section{Ireatment Compliance Measures. Throughout treaiment} phases the subjects' mothers monitored complaance with treatments by indicating on a dally basis how many times the child practiced the relaxation procedure or how much siber the child consumed. An estimate of treatment compliance was obtalned by calculating the percentage of days during treatment that the child performed the treatment. An 
Table 9

School Absenteeism and Other Activities Disrupted

\begin{tabular}{|c|c|c|c|}
\hline Sub_ect & $\begin{array}{l}\text { Parent-reported } \\
\text { School Absencea }\end{array}$ & $\begin{array}{l}\text { School } \\
\text { Attendance } \\
\text { Records b }\end{array}$ & $\begin{array}{l}\text { Activities } \\
\text { missed due to } \\
\text { stomachache }\end{array}$ \\
\hline $\mathrm{Cl}$ & $0 / 0$ & $n i a$ & no \\
\hline $\mathrm{C} 2$ & $0 / 0$ & $n i a$ & no \\
\hline $\mathrm{C} 3$ & $5 / 10$ & 5 & no \\
\hline$C 4$ & - & $n / a$ & yes \\
\hline OPl & $0 / 2$ & $n / a$ & no \\
\hline OP2 & $1 / 3$ & 9 & no \\
\hline OP3 & $3 / 8$ & 15 & no \\
\hline OP4 & $0 / 0$ & nia & no \\
\hline OP5 & $0 / 2$ & $55^{d}$ & no \\
\hline OP6 & $0 / 0$ & $\mathrm{n} / \mathrm{a}$ & no \\
\hline OP7 & $0 / 1$ & $n / a$ & no \\
\hline OP8 & $2 / 7$ & 19 & yes \\
\hline OP9 & $0 / 3$ & $n / a$ & yes \\
\hline
\end{tabular}

a last month/school year

b $n / a=$ not assessed

c Parent response to question: "Has your child missed activities le.g. scouts. symnastics, going to a relative's or friend's housel due to his/her st omachaches?"

d Number of visits to the school sick room. 
indication of overall treatment compliance was assessed by having a research assistant make two random visits to the home during each treatment phase to assess overall treatment compliance. This assistant assessed whether monitoring forms were up-to-date, complete, and easily accessible, and whether the treatment had been implemented within the last 24 hours, performed at the "usual" time las was suggested during treatment instructions), and the product necessary for treatment was easily accessible frelaxation tape or fiber: see Appendix F). An estimate of overall compliance was obtained by calculating the percentage of items observed by the research assistant during the visits for each treatment phase. Table 10 shows the percentage of motherreported treatment compliance and the percentage of overall treatment compliance as assessed by research assisstant observation.

\section{Procedures}

All subjects and at least one parent were given a verbal and written description of the study. Parents provided informed consent (see Appendix $G$ ) and children provided informed assent (see Appendix H). A letter was sent to each child's physician informing them of their patient's participation in the study, providing them with an outline of the study, and requesting that an evaluation form be completed (see Appendix I). This form requested a diagnosis 
Tabie 10

Percentage of Compliance with Treatments

\begin{tabular}{|c|c|c|c|c|}
\hline \multirow[b]{3}{*}{ Subject } & \multicolumn{2}{|c|}{ Fiber Treatment } & \multirow{2}{*}{$\frac{\text { Relaxation }}{\text { Mother }}$} & \multirow[t]{2}{*}{ Treatmen } \\
\hline & Mothe: & & & \\
\hline & Reported & Observed & Reported & Observed \\
\hline $\mathrm{Cl}$ & 73 & - & - & - \\
\hline$C 2$ & - & - & - & - \\
\hline$c 3$ & 71 & 83 & 91 & - \\
\hline $\mathrm{C} 4$ & 82 & 100 & $2:$ & 33 \\
\hline OPl & 67 & 25 & - & - \\
\hline $\mathrm{OP} 2$ & 100 & - & 66 & 50 \\
\hline OP3 & - & 100 & - & 67 \\
\hline$O P_{4}$ & 53 & 100 & - & - \\
\hline OP5 & 57 & - & 39 & - \\
\hline OFS & 90 & 100 & 50 & $: 00$ \\
\hline $\mathrm{OP} 7$ & & & 50 & 75 \\
\hline OPS & 36 & 0 & 43 & 50 \\
\hline OPS & - & - & 53 & - \\
\hline
\end{tabular}

Note. A dash $(-)$ indicates that the home vislt was not accompished tie., parent not at home research assistant unable to schedule, or plloi subject 
of the child's CI symptoms, Indication of any tests that were completed, date of the last evaluation, and if there were any additional medical procedures that ther recommended the child receive.

\section{Basel ine}

The pretreatment assessment described above was conducted at the Child Study Center for 10 subjects and at the home for three subjects. Dally monltoring and parental observation was continued throughout baseline Baselines were continued until a stable trend of stomachache $f$ reguency could be established. unless clinical judgment indicated otherwise.

\section{Treatments}

Dietary fiber. For children who met criterie for constipation. the suggested treatment was the addition of 10 grams of dietary fiber to the child's dally diet. In most cases fiber was increased through the consumption of two high fiber bars, however, in cases where the child did not like the taste of the bars, they were glven lists contalning the flber content of various food groups and a verbal contract was made between the child, the parent, and the therapist to consume foods from these lists with a total fiber content of $10 \mathrm{grams}$. Fiber consumption was monitored by the child's parent. Treatment procedures were explained by the therapist to both the parent and the child on the day 
of condition change; subsequent contact was made by phone contact, clinic or home visits.

Relaxation training and parent instruction. For

children who did not meet criteria for constipation, the suggested treatment was relaxation training. This treatment consisted of two components: (1) weekly relaxation training with the child and. (2) parental instruction on how to encourage their child to cope with their pain using the relaxation procedure. The relaxation training ltself consisted of three phases. In the first phase, the child was taught a progressive muscle relaxation technique that used tension release cycles (Jacobsen. 1939). Imagery was used to teach the child to tense and relax various muscle groups This continued until proficlency to perform the procedure had been demonstrated. as evidenced by therapist observation in session. The second phase was similar to the first except the child was taught to tense and relax the various muscie groups without the use of lmagery. In this phase, attention was given to focusing on the muscles themselves and on deep breathing. The third phase eliminated the tension-release crcles and instructed the child to relax through recalling the feelings of relaxation of "letting go" of the tension. This phase was more meditative in nature. Each relaxation procedure was about 10 minutes in length Audio tapes made by the experimenter for each procedure were provided to the 
children for home practice. Children were instructed to practice at least once per day.

Parents were instructed to change the way they respond to their child's reports of pain. Parents were to suggest that the child practice the relaxation procedure. For example, a parent who may have responded to their child's reports of pain by suggesting that the child lie down while the parent rubbed the child's stomach were taught to empathize with the child but to shift from this response to encouraging the child to practice the relaxation procedure. This process was discussed, modeled, and practiced throughout treatment. Parents monitored the frequency of the child's dally practice.

\section{Follow-up}

Four weeks after the termination of monitoring the children completed one week of dally monitoring. The parents also completed one week of dally observations and completed a follow-up form asking for a global rating of ther child's condition and how the treatment was being implemented in the home (see Appendix J).

\section{Experimental Design}

Since there was naturally occurring variability in baseline lengths subjects were treated in a multiple baseline $A-B-C$ or $A-B$ design. All of the subjects in the constipation model were treated nonconcurrently. Ali but one 
of the subjects in the operant model were treated concurrently. The order of treatment implementation was made individually based on the subject's symptom presentation. Table 6 shows the proposed model and treatment order for each of the subjects. For the subjects in the constipation model, two subjects received the suggested treatment first (dietary fiber) and two subjects received the nonsuggested treatment first followed by the suggested treatment (relaxation-dietary fiber). For the subjects in the operant learning model, four subjects received the suggested treatment first (relaxation) and five subjects received the nonsuggested treatment first followed by the suggested treatment (dietary fiber-relaxation). 
RESULTS

Subiect Characteristice

A Z-test was conducted comparing comparing the subjects' mean CDI score, for those subjects of appropriate age, with the mean score from a normative sample (Smucker, Cralghead, Craighead, and Green, 1984; $z=.51 ; 2>051$

Table 11 shows the individual scores and the mean and standard deviation for the group. No differences were found Only subject OP5 scored above the cutoff score of 19 which represents the upper $10 x$ of the distilbution

A Z-test was conducted comparing the subjects' mean score on the state and trait portions of the STAI-C, for those subjects of appropriate age, with the mean score from a normative sample ISpielberger, 1973 ; state: $z=-26$, $\mathrm{e}$; 05; tratt: $z=-1.28 ; \mathrm{p}>.05\}$. Table 11 shows the Individual scores and the mean and standard deviation for the group. No differences were found. Only subject OPS scored greater than two standard deviations above the mean on both the state and trait portions.

Table 11 shows the $t$-scores for the depressed. somatic complaints, and internalizing scales on the CBCL, as well as the group mean and standard deviation. As a group, subjects scored outside the normal range, that is, greater than two standard deviations above the mean, on the somatic complaints scale of the CBCL, while they scored within the 
Table 11

Psychological Characteristics of the Sample

\begin{tabular}{|c|c|c|c|c|c|c|c|}
\hline \multirow[b]{3}{*}{ Subj } & \multirow[b]{3}{*}{$\mathrm{CD} \mathrm{l}^{\mathrm{a}}$} & \multicolumn{2}{|c|}{$S T A I-C^{b}$} & \multicolumn{3}{|c|}{$\mathrm{CBCLC}$} & \multirow[b]{3}{*}{ EDId } \\
\hline & & & & \multirow{2}{*}{$\begin{array}{c}\text { Deppres- } \\
\text { sed }\end{array}$} & \multirow{2}{*}{$\begin{array}{c}\text { Somalic } \\
\text { Complaints }\end{array}$} & \multirow{2}{*}{$\begin{array}{l}\text { Intern- } \\
\text { aldzing }\end{array}$} & \\
\hline & & State & Irait & & & & \\
\hline $\mathrm{Cl}$ & 7 & 30 & 35 & $<55$ & 72 & 53 & 6 \\
\hline$C 2$ & $\mathrm{n} / \mathrm{a}$ & $n / a$ & $n / a$ & $<55$ & 68 & 59 & 0 \\
\hline$c 3$ & 14 & 26 & 35 & 65 & 79 & 67 & 4 \\
\hline $\mathrm{C} 4$ & $\mathrm{n} / \mathrm{a}$ & $\mathrm{n} / \mathrm{a}$ & $n / a$ & $<55$ & 68 & 55 & 2 \\
\hline $\mathrm{OPl}$ & $n / a$ & $n / a$ & $n / a$ & 71 & 85 & 73 & 9 \\
\hline $\mathrm{OP} 2$ & 10 & 30 & 38 & 73 & 78 & 73 & 20 \\
\hline OP3 & 8 & 28 & 29 & 60 & 73 & 69 & 8 \\
\hline OP4 & 12 & 30 & 31 & $<5$ & 67 & 58 & $?$ \\
\hline OP5 & 26 & 48 & 44 & 81 & 70 & 72 & 1 \\
\hline OPG & 2 & 26 & 24 & 58 & 79 & 70 & 0 \\
\hline OP7 & $n / a$ & $\mathrm{n} / \mathrm{a}$ & $n / a$ & 60 & 72 & 70 & 2 \\
\hline OP8 & 6 & 25 & 30 & 85 & 88 & 75 & 5 \\
\hline OPQ & 8 & 32 & 40 & 69 & 63 & 67 & 1 \\
\hline$H$ & 10.3 & 30.5 & 34.0 & $\langle\epsilon 4.8$ & 74.0 & 67.0 & 4.7 \\
\hline$S D$ & 6.4 & 6.5 & 5.8 & 9.9 & 7.1 & 6.1 & 5.2 \\
\hline
\end{tabular}


normal range on the depressed and internalizing scales.

A $Z$-test was conducted comparing the mothers' mear score on the BDI with the mean score from a normalive sample (Nietzel, Russell, Hemmings \& Gretter, 1987; $z=.13$, 2 ; .05). Table 11 shows the individual scores and the mean and standard deviation for the group. No differences were found. Only the mother of subject OP2 scored greater than two standard deviations above the mear.

\section{Trestment Qutcome}

\section{Constipation Model}

Four of the 13 subjects met criteria for constipation. of these four, two received the nonsuggested treatment first (1.e., relaxation training and parent instruction), followed by the suggested treatment (1.e., dietary $f(b e r)$ and the other two, who were pilot subjects, received only the suggested treatment. Figure 1 shows the weekly frequency of stomachaches across treatment phases as monitored by the subjects. Overall, each constipated subject showed reductions in the number of weekly stomachaches following the introduction of 10 grams of dietary fiber each day. In addition, for the two subjects who received the nonsuggested treatment first li.e., relaxation training and parent instruction), the frequency of stomachaches remained relatively unchanged from baseline with more consistent reductions demonstrated following the introduction of the 

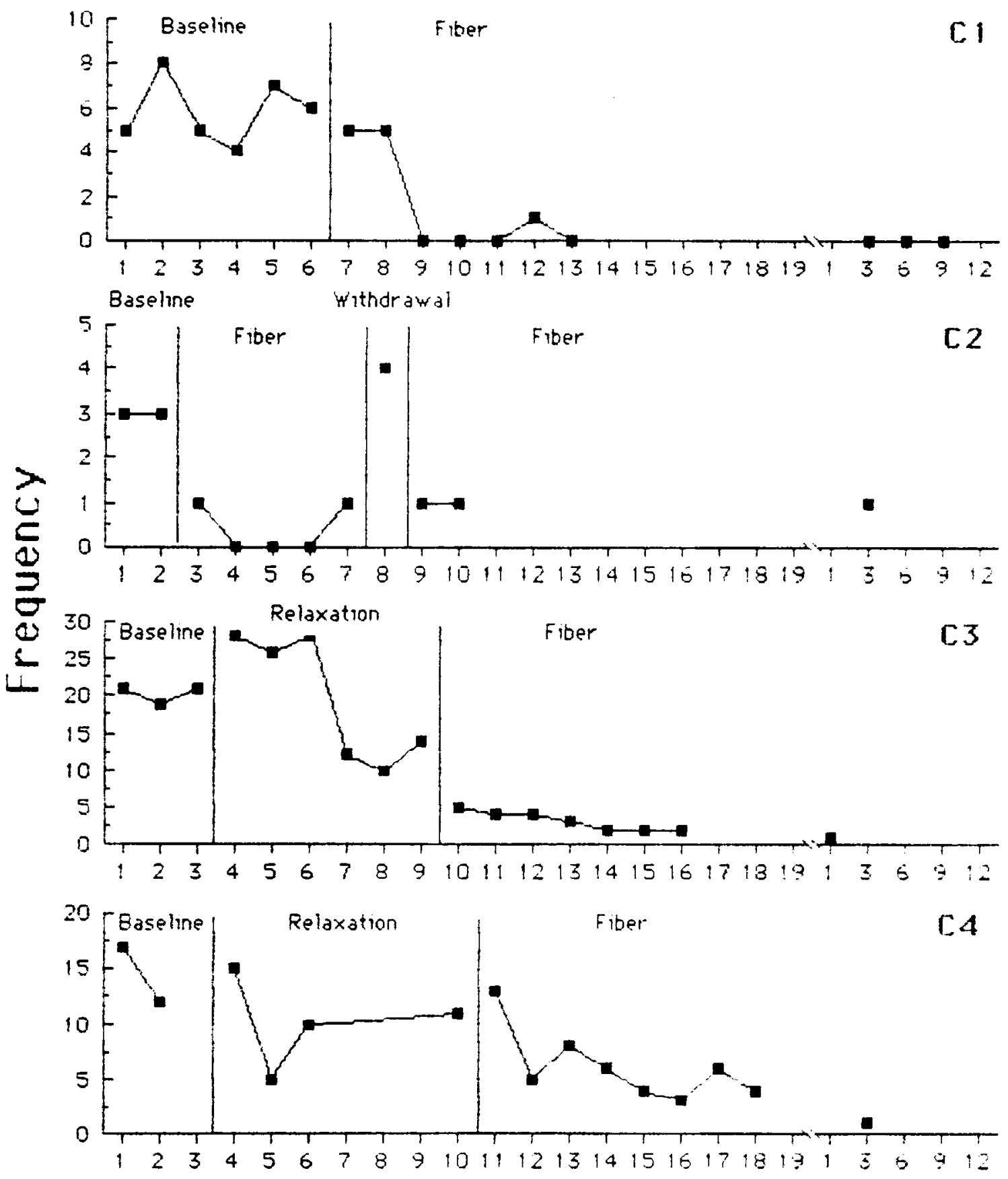

Follow up

Figure 1. Child-reported weekly stomachache frequency for subjects in the constipation model 
suggested treatment (1.e., dietary fiber). This pattern of improvement was also shown in the child index, number of pain-free days, functional indicator of pain, and parentreported frequency (see Table 12 ).

As a functional indicator of the effect of lncreased dietary fiber on bowel activity, the weekly mean frequency of bowel movements and the percentage of "hard" stools across treatment phases are shown in Table 7. Consistent with the constipation model. the three subjects with monitoring data all showed increases in bowel activity only after the introduction of the riber

Subject $\mathrm{Cl}$ was a pilot subject and recelved the suggested treatment (i.e., dietary fiber) following baseline. After a relatively stable baseline frequency of 5.8 stomachaches per week, the first two weeks of treatment showed no change. The subject's mother reported that the chlid was consuming only five grams of fiber per day. A behavioral contract was then established with the subject to consumed 10 grams per day. Subsequent to the behavioral contract, the subject showed reductions to near zero. Three, six, and nine month follow-ups showed a frequency of zero. Other measures of treatment outcome showed similar patterns of improvement (see Table 12). A reduction in intensity and an increase in the number of pain free days was shown following the fiber treatment. Parent-reported 
Table 12

Additional Qutcome Measures for Consitpated Sublects

\begin{tabular}{|c|c|c|c|c|c|}
\hline & $\begin{array}{l}\text { Child } \\
\text { Index }\end{array}$ & $\begin{array}{l}\text { Pain } \\
\text { Free } \\
\text { Days }\end{array}$ & $\begin{array}{l}\text { Functional } \\
\text { Indicator b }\end{array}$ & $\begin{array}{l}\text { Parent- } \\
\text { Reported } \\
\text { Frequency }\end{array}$ & $\begin{array}{l}\text { Parent } \\
\text { Gl obal } \\
\text { Outcome c }\end{array}$ \\
\hline $\begin{array}{l}\text { Cl } \\
\text { Basel ine } \\
\text { Fiber tx } \\
1 \text { mo. foll low-up } \\
6 \text { mo. follow-up } \\
9 \text { mo. follow-up }\end{array}$ & $\begin{array}{l}5.7 \\
2.3 \\
0.0 \\
0.0 \\
0.0\end{array}$ & $\begin{array}{l}2.2 \\
5 \cdot 5 \\
7 \cdot 0 \\
7.0 \\
7.0\end{array}$ & $\begin{array}{l}- \\
- \\
-\end{array}$ & $\begin{array}{l}- \\
- \\
- \\
-\end{array}$ & $\begin{array}{l}100 \% \\
100 x \\
100 x\end{array}$ \\
\hline $\begin{array}{l}\text { C2 } \\
\text { Basel ine } \\
F \text { iber tx } \\
\text { Withdrawal } \\
\text { Fiber tx } \\
3 \text { mo. foll ow-up }\end{array}$ & $\begin{array}{l}6 \cdot 5 \\
1 \cdot 2 \\
3 \cdot 0 \\
1 \cdot 5 \\
4 \cdot 0\end{array}$ & $\begin{array}{l}4 \cdot 0 \\
6 \cdot 6 \\
5 \cdot 0 \\
6 \cdot 0 \\
6.0\end{array}$ & $\begin{array}{l}- \\
- \\
- \\
-\end{array}$ & $\begin{array}{l}3.0 \\
0.4 \\
3.0 \\
0.5 \\
1.0\end{array}$ & - \\
\hline $\begin{array}{l}\text { C3 } \\
\text { Basel ine } \\
\text { Relax tx } \\
\text { Relax \& fiber tx } \\
\text { l mo. follow-up }\end{array}$ & $\begin{array}{r}725 \\
547 \\
\times \quad 152 \\
60\end{array}$ & $\begin{array}{l}0.0 \\
0.3 \\
4.3 \\
6.0\end{array}$ & $\begin{array}{l}0.7 \\
0.5 \\
0.0 \\
-\end{array}$ & $\begin{array}{l}2.5 \\
0.8 \\
0.6 \\
0.0\end{array}$ & $100 \%$ \\
\hline $\begin{array}{l}\text { C4 } \\
\text { Baseline } \\
\text { Relax tx } \\
\text { Relax \& fiber tx } \\
3 \text { mo. follow-up }\end{array}$ & $\begin{array}{r}23.5 \\
19.8 \\
\times 11.8 \\
2.0\end{array}$ & $\begin{array}{l}0.5 \\
1.0 \\
2.3 \\
6.0\end{array}$ & $\begin{array}{l}2.7 \\
0.0 \\
0.0 \\
0.0\end{array}$ & $\begin{array}{l}6.0 \\
4.3 \\
4.0 \\
1.0\end{array}$ & $98 x$ \\
\hline $\begin{array}{l}\text { a Index = sum of } \\
C l, C 2 \text {, \& } C 3 \text {; su } \\
\text { duration for sub } \\
\text { b Functional ind } 1 \mathrm{c} \\
\text { subjects and no } \\
\text { of days or part } 1 \\
\text { average number } \\
\text { C Parent-rated per } \\
\text { rate improvement }\end{array}$ & $\begin{array}{l}\text { the pat } \\
\text { sum of } t \\
\text { bject } \\
\text { cator of } \\
\text { data wo } \\
\text { lal days } \\
\text { of doses } \\
\text { rcentage } \\
t \text { for st }\end{array}$ & $\begin{array}{l}\text { In } 1 \mathrm{nt} \\
\text { he pr } \\
3 \\
\text { las co } \\
\mathrm{s} \mathrm{mis} \\
\mathrm{s} \text { of } \\
\text { of } \\
\text { ubject }\end{array}$ & $\begin{array}{l}\text { ensity ratin } \\
\text { oduct of int } \\
\text { ovement: Cl } \\
\text { llected; C3 } \\
\text { sed from sch } \\
\text { anti-acid me } \\
\text { mprovement; } \\
\text { C3 }\end{array}$ & $\begin{array}{l}\text { igs ior sul } \\
\text { lensity and } \\
\text { \& C2 were } \\
=\text { average } \\
\text { ool per we } \\
\text { ed lcation } \\
\text { parent di }\end{array}$ & $\begin{array}{l}\text { bjects } \\
\text { pilot } \\
\text { number } \\
\text { eek: C4 = } \\
\text { per week } \\
\text { d not }\end{array}$ \\
\hline
\end{tabular}


frequency data was not collected due to the mother being unaware of her child's stomach pain episodes. The parent rated the percentage of improvement at the three, six, and nine month follow-ups to be loox. No functional indicator of pain or estimates of treatment compliance were obtained.

Subject C2 was a pllat subject and recelved the suggested treatment (i.e. dietary fiber) following baseline. Treatment was begun after only two weeks of baseline data due to the mother self-initiating an increase in fiber during the third week. During the four subsequent weeks the child consumed an additional 10 grams of dietary fiber and showed frequency reductions to near zero. After five weeks of treatment, the fiber was withdrawn for a period of one week. During this week the stomachache frequency increased to four per week. The fiber was relntroduced and frequency levels reduced to one stomachache per week for two weeks. The three month follow-up frequency was one. The mother reported that this stomachache was accompanied by fever, ear infection, and sore throat.

Similar outcomes were obtained for intensity, pain-fiee days, and parent-reported frequency (see Table 12). No functional measure of treatment outcome, parent rated percentage of 1 mprovement, or percentages of treatment compliance were obtained. 
Subject $C 3$ received the nonsuggested treatment first (1.e., relaxation training and parent instruction), followed by the addition of the suggested treatment 11.e. dietary fiber). After a stable baseline of about 20 stomachaches per week, relaxation training and parent instruction was introduced. During this treatment the frequency increased to about 27 per week for the first three weeks and then dropped to a stable trend of about 12 per week. Following the introduction of the dietary riber, the level dropped to $\Xi i x$ the first week and continued to dropped until it stabilized to a level of two per week. One month follow-up frequency was one.

The stomachache index for subject C3 showed a $24 \%$ reduction from baseline levels during the nonsuggested relaxation treatment $164 x$ for the last three weeks of the relaxation treatment; see Table 12). A $79 x$ reduction from baseline levels was shown during the suggested fiber treatment. Similarly, pain-free days showed a substantial increase only during the flber treatment. The functional indicator of pain lnumber of missed or partially missed days of school per week\} showed only a slight reduction during the nonsuggested relaxation treatment and a reduction to zero during the suggested fiber treatment. The parentreported stomachache frequency showed a different pattern with 68x reduction from baseline levels occuring during the 
nonsuggested relaxation treatment and a $76 \%$ reduction from baseline level during the suggested fiber treatment. The parent rated the percentage of improvement at one month follow-up to be $100 x$.

No home visits were made during the nonsuggested relaxation treatment due to inability of the research assistant to find the family at home during visit times; however, the subject's mother reported a $91 \%$ compliance with this treatment. A home visit was made during the suggested fiber treatment and an overall compliance of $83 x$ was observed by the research assistant. The mother-reported treatment compliance was $71 \%$ during this treatment lsee Table 10).

Subject $C 4$ received the nonsuggested treatment first (1.e. relaxation training and parent instruction), followed by the addition of the suggested treatment 11.e., dietary fiberl. For the first two weeks of baseline the subject reported an average of 14.5 stomachaches per week. The subject's monitoring data was unavallable for the third week due to a holiday. The mother's self-report of the child's stomachache frequency during baseline was stable at six per week. During the first week of the nonsuggested relaxation ireatment the rate of stomachaches was 15 , dropped to rive in the second week, then increased during weeks $s 1 x$ and 10 to an average of 10.5 per week. The data for weeks seven 
through nine were reportedly lost by the subject. The suggested treatment was instituted on week 11 . During this treatment a steady reduction in stomachache frequency was reported by the subject from a high of 13 during week 11 to a rate of between three and four. The frequency at three month follow-up was at one

The stomachache index and pain-free days shows a similar pattern of some improvement during relaxation with most improvement occurring during the dietary riber treatment (see Table 12). The parent-reported frequency showed a different pattern: a mean baseline frequency of $s i x$ per week dropped to mean of 4.3 per week during the relaxation treatment. This represents a $28 x$ reduction. A rate of 4 per week was reported during the relaxation plus flber treatment. The frequency during the three month follow-up was one. The functional indicator of pain dropped off following the introduction of the relaxation and parent instruction treatment and remained at zero through followup. The parent rated the percentage of improvement at the three month follow-up to be $98 x$

During the nonsuggested relaxation treatment an overall compliance of $33 x$ was observed by the research assistant and a treatment compliance of $21 \%$ was reported by the mother. Compliance was better during the first three weeks of the relaxation treatment but dropped off during the last three 
weeks of treatment as mother and child "lost interest". Compliance increased during the relaxation plus the suggested fiber treatment with an overall compliance of $100 \%$ as observed by the research assistant and a treatment compliance of $82 x$ as reported by the mother (see Table 10). Operant Learning Model

Nine of the 13 subjects did not meet criteris for constipation and were, therefore, treated under the operant learning model. Of these nine, five subjects received the nonsuggested treatment first (1.e., dietary fiber) followed by the suggested treatment li.e, relaxation training and parent instruction). Four subjects, one of which was a pilot subject (OP9), received the suggested treatment first

Figures 2 and 3 show the child-reported weekly frequency of stomachaches across treatment phases. Overall, six of the nine subjects showed a reduction in the rate of stomachaches by at least $50 x$ below baseline levels following some form of treatment. Of the five subjects that received the nonsuggested treatment first (i.e., fiber), three showed substantial reductions in the rate of stomachaches during this treatment. In the other two, little improvement was shown during the nonsuggested treatment and more substantial improvement followed the introduction of the treatment suggested by the operant learning model fi.e., relaxation and parent instruction). Of the four subjects that recelved 


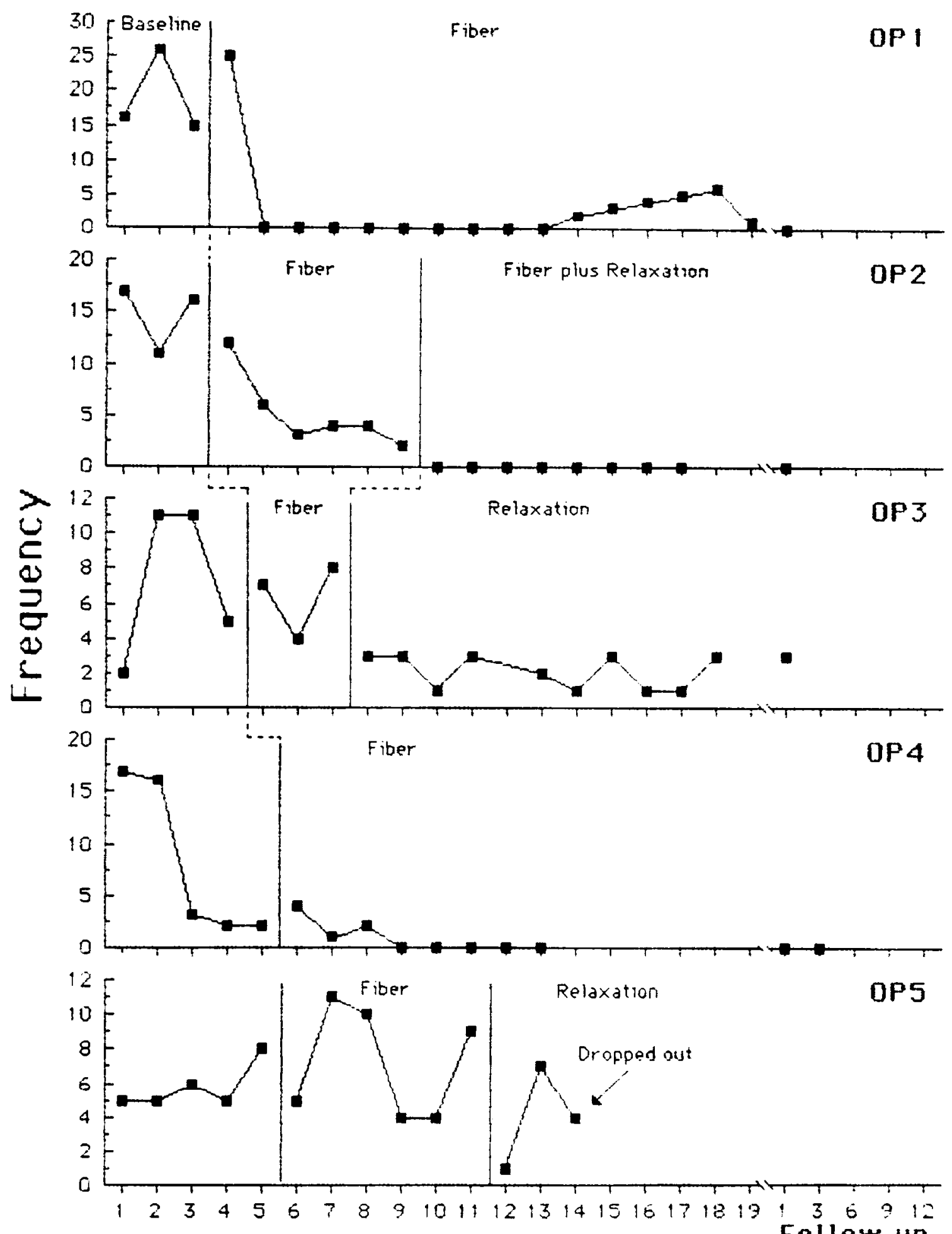

Follow up

Elgure 2. Week!y stomachache frequency for operant learning subjects. All five subjects received the nonsuggested fiber treatment first 


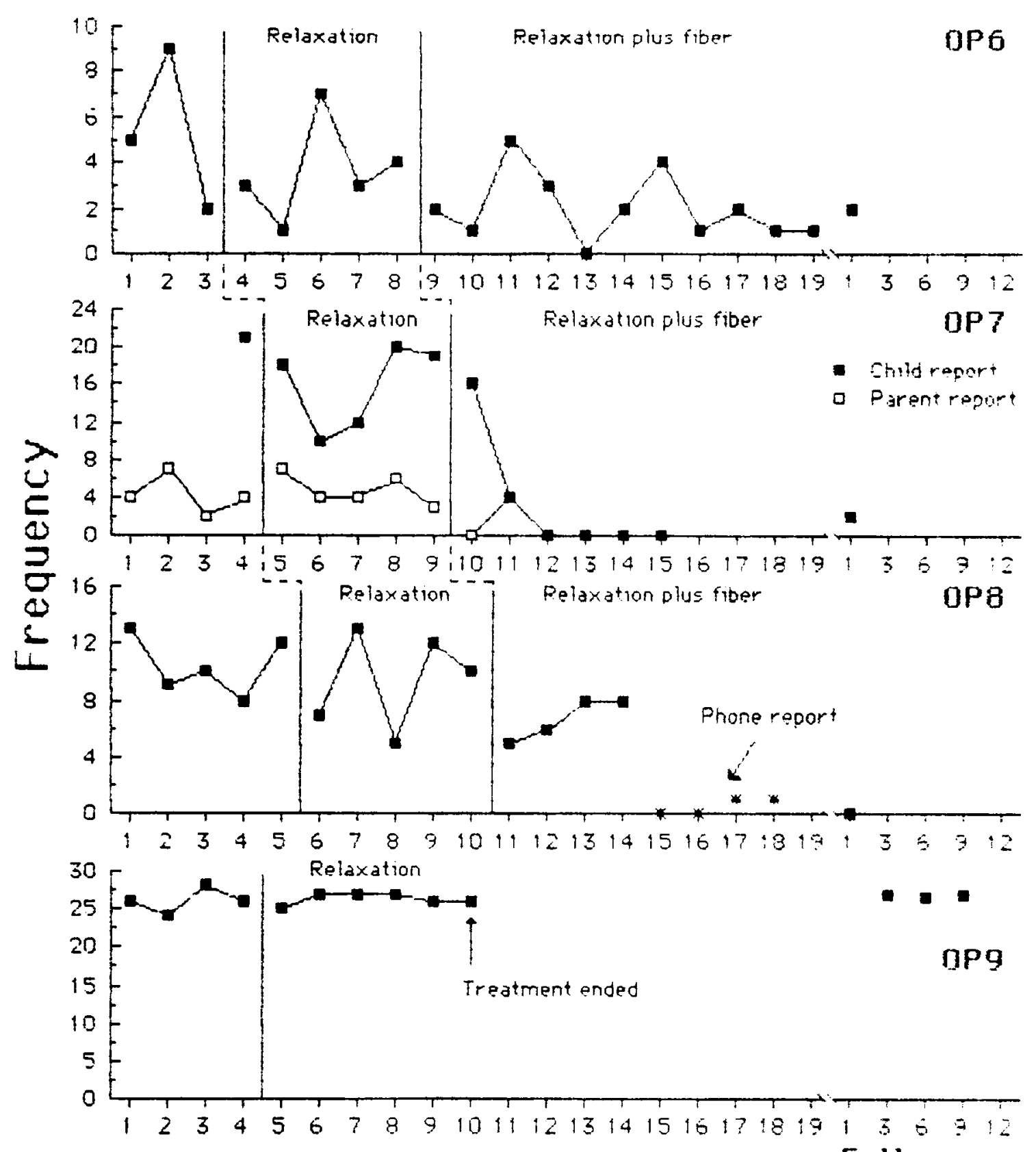

Follow up

Figure 3. Weekly stomachache frequency for operant learning subjects. All four subjects recelved the suggested relaxation training and parent instruction treatment $f: s t$ 
the suggested trealment first li.e., relaxation and parent instructionl, none showed meaningful reductions during the course of this treatment. For two of these, a reduction in stomachache frequency was demonstrated only after the nonsuggested treatment was added $\{1 . e$, fiber $\}$. Similar patterns of 1 mprovement were also demonstrated across the other outcome measures (see Table 13).

Subject OPl received the nonsuggested treatment following baseline (1,e., dietary fiber). A mean frequency of 19 stomachaches per week was shown over baseline. The baseline level was somewhat variable but since it was at such a high rate treatment was initiated after the third week. The first week of the nonsuggested fiber treatment showed an increase in rate of stomachaches to 25; however, the subsequent nine weeks remalned at a rate of zero. Weeks 14 through 19 showed a slight increase which peaked at five stomachaches per week. During these weeks, the subject's mother revealed that they had falled to supplement with dietary fiber following a family vacation. Once fiber was reinstiluted, the rate began coming down. Both child and parent became unieliable in recording the monitoring data after the seventh week. Data for weeks elght through is were obtained by weekly phone contacts. The frequency al one month follow-up was zero.

Due to the unrellability of monitoring during 
Table 13

Additional Outcome Measures for Operant Learning Subjects

\begin{tabular}{|c|c|c|c|c|c|}
\hline & $\begin{array}{l}\text { Child } \\
\text { Index a }\end{array}$ & $\begin{array}{l}\text { Pain } \\
\text { Free } \\
\text { Days }\end{array}$ & $\begin{array}{l}\text { Functional } \\
\text { Indicator b }\end{array}$ & $\begin{array}{l}\text { Parent- } \\
\text { Reported } \\
\text { Frequency }\end{array}$ & $\begin{array}{l}\text { Parent } \\
\text { Global } \\
\text { Outcome } 6\end{array}$ \\
\hline $\begin{array}{l}\text { OPl } \\
\text { Basel ine } \\
\text { Fiber tx } \\
\text { l mo. follow-up }\end{array}$ & $\begin{array}{l}- \\
-\end{array}$ & $\begin{array}{r}0.7 \\
>4.8 \\
7.0\end{array}$ & $\begin{array}{l}- \\
-\end{array}$ & $\begin{array}{l}6.3 \\
1.6 \\
0.0\end{array}$ & $70 x$ \\
\hline $\begin{array}{l}\text { OP2 } \\
\text { Baseline } \\
\text { Fiber tx } \\
\text { Fiber \& relax tx } \\
\text { l mo. follow-up }\end{array}$ & $\begin{array}{r}1833 \\
1252 \\
0 \\
5\end{array}$ & $\begin{array}{l}1.0 \\
4.8 \\
7.0 \\
6.0\end{array}$ & $\begin{array}{l}0.7 \\
0.5 \\
0.0 \\
-\end{array}$ & $\begin{array}{l}3.7 \\
1.8 \\
0.0 \\
1.0\end{array}$ & $70 \%$ \\
\hline $\begin{array}{l}\text { OP3 } \\
\text { Basel ine } \\
\text { Fiber tx } \\
\text { Relax tx } \\
\text { l mo. follow-up }\end{array}$ & $\begin{array}{l}499 \\
613 \\
207 \\
185\end{array}$ & $\begin{array}{l}2.3 \\
2 \cdot 3 \\
5.1 \\
5.0\end{array}$ & $\begin{array}{l}0.5 \\
0.7 \\
0.2 \\
-\end{array}$ & $\begin{array}{l}- \\
- \\
-\end{array}$ & $70 x$ \\
\hline $\begin{array}{l}\text { OP4 } \\
\text { Basel ine } \\
\text { Fiber tx } \\
\text { l mo. follow-up }\end{array}$ & $\begin{array}{r}1155 \\
123 \\
0\end{array}$ & $\begin{array}{l}3.6 \\
6.3 \\
7.0\end{array}$ & $\begin{array}{l}2.2 \\
0.0 \\
0.0\end{array}$ & $\begin{array}{l}4.0 \\
0.3 \\
0.0\end{array}$ & $100 \%$ \\
\hline $\begin{array}{l}\text { OPS } \\
\text { Basel Ine } \\
\text { Fiber tx } \\
\text { Relax tx } \\
\text { Follow-up }\end{array}$ & $\begin{array}{l}10.0 \\
14.8 \\
7.3\end{array}$ & $\begin{array}{l}3.4 \\
3.3 \\
4.7 \\
-\end{array}$ & $\begin{array}{l}1.5 \\
1.5 \\
0.6 \\
0.9\end{array}$ & $\begin{array}{l}4.2 \\
4.7 \\
3.0\end{array}$ & - \\
\hline
\end{tabular}

a Index $=$ sum of the product of intensity and duration for subjects OP2, OP3, \& OP4; sum of the pain intensity ratings for subjects OP5

b Functional indicator of improvement: OPl: no functional indicator was found: OP2 \& OP3: average number of days or partial days missed from school per week: OP4: average number of doses of antacid medication per week; OP5: average number of visits to the school sick room per week

$c$ Parent-rated percentage of improvement 
Table 13 cont.

Additional Outcome Measures for Operant Learning Subjects

\begin{tabular}{|c|c|c|c|}
\hline$\frac{d}{x} 8$ & $\begin{array}{l}\text { Pain } \\
\text { Free } \\
\text { Days }\end{array}$ & $\begin{array}{l}\text { Functional } \\
\text { Indicator } b\end{array}$ & $\begin{array}{l}\text { Parent- } \\
\text { Reported } \\
\text { Frequency }\end{array}$ \\
\hline
\end{tabular}

\begin{tabular}{|c|c|c|c|c|c|}
\hline $\begin{array}{l}\text { OP6 } \\
\text { Basel ine } \\
\text { Relax tx } \\
\text { Relax \& flber tx } \\
\text { l mo. follow-up }\end{array}$ & $\begin{array}{l}430 \\
545 \\
127 \\
130\end{array}$ & $\begin{array}{l}3.5 \\
4.4 \\
5.0 \\
5.0\end{array}$ & $\begin{array}{l}3.5 \\
0.0 \\
0.0 \\
0.0\end{array}$ & $\begin{array}{l}2.7 \\
2.2 \\
1.9 \\
2.0\end{array}$ & $50 \%$ \\
\hline $\begin{array}{l}\text { OP7 } \\
\text { Basel Ine } \\
\text { Relax tx } \\
\text { Relax of fiber tx } \\
\text { l mo follow-up }\end{array}$ & $\begin{array}{l}- \\
- \\
-\end{array}$ & $\begin{array}{l}0.0 \\
0.0 \\
6.0 \\
5.0\end{array}$ & $\begin{array}{l}- \\
- \\
-\end{array}$ & $\begin{array}{l}4.3 \\
4.8 \\
0.7 \\
2.0\end{array}$ & $90 \%$ \\
\hline $\begin{array}{l}\text { OPB } \\
\text { Basel ine } \\
\text { Relax tx } \\
\text { Relax \& fiber tx } \\
\text { l mo.follow-up }\end{array}$ & $\begin{array}{r}1666 \\
578 \\
375 \\
0\end{array}$ & $\begin{array}{l}1.4 \\
2.2 \\
3.3 \\
7.0\end{array}$ & $\begin{array}{c}0.4 \\
0.4 \\
- \\
-\end{array}$ & $\begin{array}{l}2.5 \\
3.2 \\
1.5 \\
0.0\end{array}$ & $40 \%$ \\
\hline $\begin{array}{l}\text { OPg } \\
\text { Basel ine } \\
\text { Relax tx } \\
6 \text { mo. foll ow-up } \\
9 \text { mo. follow-up }\end{array}$ & $\begin{array}{l}71 \\
67 \\
44 \\
58\end{array}$ & $\begin{array}{l}0.0 \\
0.0 \\
0.0 \\
0.0\end{array}$ & $\begin{array}{l}- \\
- \\
-\end{array}$ & $\begin{array}{l}7.0 \\
7.0 \\
7.0 \\
7.0\end{array}$ & $\begin{array}{r}25 x \\
0 x\end{array}$ \\
\hline
\end{tabular}

a Index $=$ sum of the pain intensity ratings for subjects OFo \& OP9; sum of the product of intensity and duration for subject OP8

b Functional indicator of improvement: OPG: average number of days that allergy medication was taken per week, OF $7 \hat{\alpha}$ OP9: no functional indicator was found: OPB: average number of days or partial days missed from school

C Parent-rated percentage of Improvement

d Subject OPB provided monitoring data for only the first four weeks of this treatment. weekly phone reported was obtalned for the subsequent four week, however, the scores reported here are based on the first four weeks of this treatment only 
treatment, the stomachache index could not be calculated The outcome measures of pain-free days and parent-reported frequency showed improvements similar to that described above (see Table 13). A functional indicator of pain that was distinct from verbal report or parent observation was not found. The parent rated the percentage of improvement at one month follow-up to be $70 x$

During the nonsuggested riber treatment an overall compliance of $25 \%$ was observed by the research assistant and for the first four weeks of treatment the mother reported the treatment compliance to be $67 \%$ (see Table 10 ).

Subject OP2 received the nonsuggested treatment following baseline (1.e., dietary fiber). A mean fiequency of 14.7 stomachaches per week was shown over baseline. During the course of the nonsuggested fiber treatment, the rate of stomachaches showed steady reductions from a high of 12 during the first week to a low of two. Similar lmprovements were shown in the number of pain-free days reported by the subject and the parent-reported frequency (see Table 13).

A different pattern was shown when the stomachache Index (sum of the product of intensity and duration) and functional measure of pain lnumber of days or partial days missed from schooll were considered as outcome measuies (see Table 13). Although the subject was having much iewer 
stomachaches, the subject's stomachache index indicated that the stomachaches that were occurring were, on average, of greater intensity and longer duration than of those that occurred during baseline. The subject had also missed one day of school each week for the last three weeks of the fiber treatment as a result of stomachaches. Due to the later outcome, a cinnical judgment was made to add the suggested treatment li.e., relaxation and parent Instruction) to the riber treatment. Subsequent to the addition of the suggested treatment the subjects rate dropped to zero and stayed there for elght weeks. The frequency at the one month follow-up was zero. The parent rated the percentage of improvement at one month follow-up to be $75 x$.

No home visits were made during the nonsuggested iber treatment due to inability of research assistant io find the family at home during visit times. Treatment compliance during the fiber treatment was $100 x$ as reported by the mother. A home visit was made during the suggested relaxation treatment and an overall compliance of $50 \%$ was observed by the research assistant. Treatment compliance during the relaxation treatment was $66 \%$ as reported by the mother (see Table 10).

Subject OP3 recelved the nonsuggested treatment fist (1.e., dietary fiber), followed by the suggested ireatment 
(1.e., relaxation training and parent instruction). During baseline the frequency of stomachaches each week was varlabie, with a range of two to 11 and a mean of 7.3 per week. Following the introduction of the nonsuggested fiber treatment, the rate of stomachaches remained variable with a range between four and eight and a mean of 6.3 per week. The suggested relaxation and parent training treatment was introduced after three weeks of the nonsuggested fiber treatment. During the suggested relaxation treatment the rate dropped and remained fairly stable with a range of one to four and a mean of 2.2 per week.

The ineffectiveness of the nonsuggested fiber treatment and the effectiveness of the suggested relaxation treatment is elearer for subject OP3 when the other measures of treatment outcome are considered (see Table 13). During the nonsuggested fiber treatment the subject's stomachache index increased by 19\%, the functional indicator of pain increased by $28 \%$, and the number of pain-free days remalned the same During the suggested relaxation treatment the child's stomachache index decreased to a level that was 58\% below baseline, the functional indicator of pain decreased to $60 \%$ below baseline, and the number of pain-free days increased to $45 x$ above baseline. Parent-reported frequency data was not collected due to the mother being unaware of her child's stomach pain episodes. At the one month follow-up, the 
frequency was three and the child's stomachache index declined. The parent rated the percentage of 1 mprovement at one month follow-up to be $70 x$.

Overall compliance, as observed by the research assistant, was $100 x$ during the nonsuggested iber treatment and $67 \%$ during the suggested relaxation treatment. The subject's mother did not reliably monitor the subject's treatment compliance during treatments (see Table 10 :

Subject OP4 received the nonsuggested treatment following baseline (i.e., dietary fiber). The frequency of stomachaches for the first two weeks of baseline was 17 and 16. respectively. The rate dropped to three during the thisd week and to two during weeks four and flve. The nonsuggested fiber treatment was introduced on week $51 x$. During this treatment the rate increased to four during week $s i x$ and then showed a trend to zero by week mine. The rate remained at zero through week 13. The reduction of stomachache frequency during baseline makes it difficult to confidently determine whether the change observed during treatment was due to the effects of treatment or to other nonspecific effects. The frequency at one and three month follow-ups were zero.

The other measures of treatment outcome showed a similar trend toward improvement during baseline which continued through treatment (see Table 13). The parent rated 
the percentage of 1 mprovement at one month follow-up to be $100 x$.

Overall compliance was $100 x$ as observed by the research assistant. Treatment compliance was $57 x$ as reported by the mother (see Table 10 ).

Subject OP5 received the nonsuggested treatment first (1.e., dietary fiber), followed by the suggested treatment (1.e., relaxation). The frequency of stomachaches showed an increasing trend through baseline with a mean irequency of 5.8 stomachaches per week. During the nonsuggested $r$ ibe: treatment the rate was variable with a range of four to II and a mean of 7.2 per week. Following the introduction of the suggested relaxation treatment the rate was variable with a range of one to seven and a mean of four per week. After completing the third week of this treatment the fam:1\% dropped out of treatment for personal reasons.

The other measures of treatment outcome reflected a trend toward improvement following the introduction of the suggested relaxation treatment (see Table 13). Of interest is the $60 x$ reduction in the functional indicator of pain during the time that the relaxation treatment was in effect This rate increased after the famly dropped out of treatment. The subject's mothey did not respond to follow-up requests. 
Home visits were not made during treatment to assess overall treatment compliance because the mother reported that she felt uncomfortable having someone come to her home. Treatment compliance, as reported by mother, was 57\% during the fiber treatment and $38 x$ during the relaxalion treatment (see Table 10 ).

Subject OP6 received the suggested treatment following baseline (1.e., relaxation training and parent instruction) The frequency of stomachaches was variable through baseline with a mean of 5.3 stomachaches per week. The effect of the relaxation treatment is difficult to assess for two reasons. First, during the third week of baseline there was a trend toward improvement which makes it difficult to confidentiy determine whether the subsequent change was due to the effects of treatment or to other nonspecific effects Secondly, results from the other measures of treatment outcome were mixed (see Table 13). Throughout the suggested relaxation treatment the rate of stomachaches as reported by the child continued to be variable; however, the mean decreased to 3.6 per week. Similar improvement was shown in the number of paln-free days. However, the stomachache index increased, indicating that although the subject was having less stomachaches, the intensity and duration of the stomachaches had increased. Parent-reported frequency aiso showed little reduction over baseline levela. The functiona: 
indicator of pain dropped of to zero imediately following the introduction of the relaxation treatment.

The nonsuggested fiber treatment was introduced after five weeks of the relaxation treatment. Since the effect of the relaxation treatment alone was inconclusive, a clinical decision was made to add the fiber treatment to the relaxation treatment, even though the subject's symptom presentation did not suggest that the subject was constipated. During the relaxation and fiber treatment, the frequency of stomachaches continued to be variable but the mean number of stomachaches per week decreased to two. In addition. the stomachache index decreased to $70 \%$ below baseline. The number of pain-free days and mother-reported frequency continued to show slight improvement. The childreported frequency at one month follow-up was two. The parent rated the percentage of improvement at one month follow-up to be $50 x$.

Overall compliance during the suggested relaxation and parent instruction treatment was $100 x$ as observed by the research assistant. Treatment compliance was $66 \%$ as reported by the mother. The overall compliance during the relaxation plus fiber treatment was $100 x$ as observed by the research assistant. Treatment compliance was $80 x$ was reported by the mother (see Table 10). 
Subject OP7 received the suggested treatment following baseline (1.e., relaxation training and parent instruction) The subject had difficulty with monitoring and the data were considered unreliable, therefore, the only measures of treatment outcome presented here are the child's montiored frequency, the number of pain free days, and the parentreported frequency. A functional indicator of pain that was distinet from verbal report or parent observation was not found. The frequency of stomachaches, as reported by the mother, varied from two to seven per week with a mean of 4.3 per week. The frequency of child-reported stomachaches was 21 for the last week of baseline. The rate, as reported by mother, remained fairly stable at 4.8 per week during the suggested relaxation treatment. The child's reported frequency was variable with no clear trend, ranging from 10 to 20 with a mean of 15.8 per week.

The nonsuggested fiber treatment was introduced after Iive weeks of the relaxation treatment. Following the introduction of fiber, the child's frequency was 16 and tire mother-reported frequency dropped to zero for the first week. From weeks 11 through 15, the subject spent a vacation with her grandmother. The grandmother helped the child monitor during these weeks and the grandmother was instructed by the mother in how to administer the fiber. The child-report frequency dropped to faur the second week of 
the fiber and relaxation treatment, dropped to zero the third week and stayed at zero through the sixth week of treatment. The one month follow-up frequency was two. The parent rated the percentage of improvement at one month follow-up to be $90 x$.

Overall compliance during the suggested relaxation and parent instruction treatment was $75 \%$ as observed by the research assistant. Treatment compliance was $60 \%$ as reported by the mother. Treatment compliance during the relaxation plus fiber treatment was $71 \%$ during the flrst week of this treatment (see Table 10). Compliance for the remaining weeks were not available.

Subject OPB recelved the suggested treatment following baseline (i.e., relaxation training and parent instruction). During baseline the frequency of stomachaches was relatively stable with a range of eight to 13 and a mean of 10.4 per week. Following the introduction of the suggested relaxation treatment, the weekly frequency was variable with no clear trend, ranging from five to 13 stomachaches per week with a mean of 9.4 per week. The other measures of treatment outcome were mixed (see Table 13). The subject showed a $65 \%$ improvement in the stomachache index during the relaxation treatment. The number of pain-free days slightiy increased. the functional indicator of pain remained the same, and the parent-reported frequency increased. 
The nonsuggested flber treatment was introduced after five weeks of the relaxation treatment. Following the introduction of fiber, the rate of stomachaches dropped to five and showed a gradually increasing trend to eight after the fourth week and a mean of 6.8. Data were avallable for only the first four weeks of this treatment due to noncompliance. These data showed improvement in the stomachache index, pain-free days, and parent-reported frequency. Weekly phone contact for the subsequent four weeks showed marked reductions in the rate of stomachaches, however, the fiber had been discontinued during this time by the subject's mother because they "lost interest". The one month follow-up frequency was zero. The parent rated the percentage of improvement at one month follow-up to be $40 \%$ The overall compliance during the suggested relaxation and parent instruction treatment was $50 x$ as observed by the research assistant. Treatment compliance was $43 x$ as reported by the mother. Treatment compliance during the relaxation plus fiber treatment was $36 \%$ as reported by the mother. The overall compliance was not observed during this treatment (see Table 10).

Subject OP9 was a pilot subject and received the suggested treatment following baseline li.e., relaxation training and parent instructionl. During baseline the frequency of stomachaches was stable with a mean of 26 per 
week During the relaxation and parent instruction treatment, the weekly frequency showed little change for the seven weeks of treatment with a mean of 26.6 per week. The other outcome measure also remained relatively unchanged Isee Table 10). Three, six, and nine month follow-ups showed no change in the child or mother-reported rate of stomachaches. The parent rated the percentage of improvement at follow-up to be $25 \%$. It should be noted that in addition to a diagnosis of functional abdominal pain, her pediatrician also diagnosed this subject as having tenderness over the right pelvic kidney and a compensatory short right ureter. 


\section{DISCUSSION}

The hrpothesis that presenting symptoms in children with RAP provide a basis for treatment selection was only partially supported. In general, support was obtained for the constipation model for children with presenting symptoms of constipation. All four of the subjects showed substantial improvement following the introduction of a dietary fiber treatment. The operant learning model was not well supported for children without presenting symptoms of constipation. Two of the nine subjects showed improvements that were supportive of the model following the introduction of a relaxation treatment.

The first three hypotheses, predicting that the present sample would display more depression, anxiety, internalization, and maternal depression, were not supported. Subjects did, however, have higher scores on somatic complaints, consistent with their diagnoses. There were some similartities and differences between the present sample and previous samples. As in previous studies, depression was not associated with RAP. lHodges et al., 1985a; MeCrath et al., 1983; Raymer et al., 19841. The present sample differed from previous samples in that the children were less anxlous and the mothers were less depressed (Hodges et al., 1985b; Hodges et al.. 1985a) 
With the exception of two single case studies (Miller \& Kratochw111, 1979; Sank and Biglan, 19741, previous outcome studies for RAP have used group analyses and global eriterion to evaluate treatment effectiveness. $50 \%$ of experimental (fiber) group in the Feldman et al. situdy showed at least a $50 x$ reduction in pain episodes in response to dietary fiber: $75 \%$ of the ireatment group in the Sanders et al. (1989) study were pain-free following a mult1component cognitive-behavioral treatment; and $81 \%$ of the Finney et al. (1989) sample reported an improvement or resolution of pain srmptoms following a multicomponent treatment package. When the present outcome is looked at as a group using a global criteria of success the results are similar to previous studies: about $70 x$ showed improvements of $50 x$ or greater reduction in pain complaints and on other outcome measures following treatment. However, the course of treatment for individual subjects becomes obscured in group analysis. The use of single subject methodology helps to identify the true course of treatment response, with trends in baseline suggesting caution in interpretation. In addition, single subject analysis allows for the examination individual characteristics that are associated with improvement and to observe the extent of change in the individual subjects. 


\section{Constipation Model}

All of the subjects in the constipation model showed improvement in self-reported frequency of stomachaches, stomachache index, pain-free days, and parent-reported frequency following the introduction of the dietary fiber treatment. Three of the four subjects responded dramatically to the introduction of dietary fiber $(\mathrm{Cl}, \mathrm{C2}, \&$ C3): ite fourth showed less dramatic improvement $|\mathrm{C} 4|$. The predictive value of using symptoms of constipation as a test of positive treatment response to a dietary fiber treatment was 100\% (four of four). The presence of symptoms of constipation, as defined in the present studr, is a good indicator of positive response to supplementing dietary flber by at least 10 grams per day. However, ilve subjects subjects who did not meet criterion for constipation responded positively following an increase in dietary fiber Two subjects $(O P 1 \&$ OP7) showed substantial improvement, while three subjects $10 P 2$, OP4, \& OP6) responded less dramaticaliy. A lack of constipation symptoms, therefore, was not a good predictor of negative treatment response to fiber; with four of nine (44x) showing a lack of response to the flber treatment. The absence of symptoms of constipation, as defined by the present study, does not appear to be a good indicator of a negative response to a fiber treatment. 
One explanation for the number of false negatives is that the indices of frequency and consistency as criteria for constipation may be too indirect a measure of the mechanism thought to be producing the abdominal pain Constipation symptoms have been proposed to be the result of increased distal bowel activity (i.e., high amplitude contractions) and abnormal bowel transit times (Feldman et al. 1985; Whitehead \& Schuster, 1985). Although bowel movement frequency has been correlated with prolorged transit time, not all children with prolonged transit time will have reduced bowel frequency (Corazzlar1, Cucchiara, Stalano, Romaniello, Tamburrini, Torsoli, \& Auricchio. 1985). A child with slow transit time may pass small stools frequently. A more direct measure of gastrointestinal transit time (see Corazziarl et al., 1985) or colonic motility (see Whitehead, Engel, \& Schuster, 1980 ) may provide better predictors of response to a fiber treatment

An alternative explanation for the results of the constipation model is that the improvement was a function of nonspecific effects of the treatment process or just the passage of time. Two controlled treatment studies of RAP have reported spontaneous improvements in control subjects Christensen (1986) described the results of a double-blind. randomized, controlled investigation on the effects of a bulk preparation with 31 children with RAP. No differences 
in the frequency of abdominal pain were found between the groups; however, a total of 17 children from both groups showed reductions in frequency of abdominal pain. In addition, a controlled group treatment study by Sanders et al. (1989) using a multicomponent cognitive-behavioral treatment package also showed improvements in the control group. The reason for these spontaneous remissions remalns unclear. In the present study, it appears less likely that the effects of the fiber treatment were nonspecific or time related for three reasons. First, experimental control of the $f$ iber treatment was demonstrated in one subject $(\mathrm{C} 2)$ by withdrawing the treatment in an $A-B-A-B$ design isee Figure 1). Secondly, the relative lack of improvement in two subjects following a treatment that was not thought to be related to the presenting symptoms of constipation ilie., relaxation trainingl makes it unlikelr that the effects were due to nonspecific or sequencing effects. Thirdly, consistent reductions were only shown following the introduction of the siber treatment.

The present study provided empirical support for utilizing constipation symptoms as a predictor of positive response to a dietary flber treatment; however, the number of subjects without constipation symptoms who responded positively to the fiber treatment ralses some questions about the most appropriate criterion for inclusion in the 
constipation model. The cutoff criterion for the number of bowel movements per week that indicate constipation may have been too conservative leading to a number of false negatives. Part of the difficulty in establishing an appropriate cutoff is that definitions of constipation have traditionally been based on clinical impression rather than physiological variables (Corazziari et al., 1985). In an investigation of 78 pediatric patients referred for chronic nonorganic constipation Corazziari and his colleagues 11985 , reported the mean weekly frequency of bowel movements to be 6.3 (range 4 to 9). Post-hoc inspection of Tabies 7 and 8 reveal that if the criteria for inclusion in the constipation model were set at less than six bowel movements per week, at least three-more valid positives would have been predicted while adding one false negative and one faise positive. Further investigation is needed to establish the validity of using bowel movement frequency and consistency as predictors of the effects of a fiber treatment. In addition. studies using larger sample sizes are need to establish cutoff criterion that would maximize the number of valid positives while minimizing the number of false negatives.

The results of the present study provide some support for the effectiveness of a dietary fiber treatment for children with symptoms of constipation and indirect support 
for the role of constipation in the etiology and maintenance of RAP in a subgroup of children. Further research is reeded to identify more directly the mechanisms involved in this subgroup of children and to develop measures which would be more predictive of positive and negative responses to a dietary fiber treatment

Operant Learning Model

In the operant learning model only two of the nune subjects (OP2, OP3) responded in a way that was supportive of the model. The predictive value of using the lack of constipation symptoms as a test of positive treatment response to teaching children relaxation skills and teaching parents to encourage their children to cope when the child complained of stomach pain was only $25 \%$ (two of elght). The lack of constipation symptoms, therefore, does not appear to be a sufficient indicator of positive response to relaxation and parent instruction treatment.

The relaxation and parent instruction treatment appears to have had some specific effects. One subject $|O P 3|$ showed no improvement in any of the outcome measures during the fiber treatment; improvement was shown on all outcome measures following the introduction of the relaxation and parent instruction treatment; however, the symptoms were not resolved and improvement was less dramatic than was seen for several subjects that responded to the fiber treatment. A 
second subject (OP2) responded to the fiber treatment with reductions in the frequency of stomachaches but relativel: little change in the number of days missed from school. Improvement in this functional indicator of pain occurred only after the introduction of the relaxation and parent instruction treatment. The results of this subject must be interpreted cautiously; since improvement was shown during the fiber treatment. It is difficult to determine whether the reduction in the number of dars missed from school was due to the relaxation treatment or the continued effects of the fiber. A similar reduction in the functional indicator of pain was shown in another subject (OP5). This subject showed no improvement during the fiber treatment but began to show improvement in most outcome measures during the first three weeks of the relaxation and parent instruction ireatment before dropping out of the studr. It is interesting to note that this subject showed a box reduction in the weekly number of visits to the school sick room after the relaxation and parent training treatment was introduced and that the number of visits increased after ther dropped out of treatment (see Table 13). It appears from these subjects that relaxation training and parent instruction may, for some subjects, have specific effects related to subjective, objective, and functional measures of pain. 
There are several problems with trying to evaluate the relaxation and parent instruction treatment as a test of the operant model. First, some of the subjects may have had more subtle srmptoms of constipation, as indicated by their response to the fiber treatment. Secondly, since there were two components to the relaxation and parent instruction treatment, it is not possible to determine whether the positive response was due to an actual change in the parentchild interaction or whether it was due to autonomic quiescence resulting from the relaxation procedure itself Further research is needed to determine the relative effectiveness of these components. Thirdly, the relaxation and parent instruction treatment attempted to change the contingencies thought to be maintaining the RAP symptoms by structuring the parent-child interaction toward coping with pain symptoms by teaching the parent to encourage their child to practice the relaxation procedure when the child complained of stomach pain. However, since a measure of the parent-child interaction was not obtained, it is difficult to determine what effect the treatment had on the parentchild interaction. Such data would have been helpful in analyzing treatment successes and failures.

In addition to the problems mentioned above, one of the potential problems of the present study is the fallure to define psrchogenic inclusion criteria for the operant 
learning model; rather than placing a subject in the operant learning model on the basis of lack of constipation symptoms alone, using evidence of the reinforcement process may have been a more appropriate inclusion criteria. For example, the amount of school missed due to illness may be used as an indirect measure of negative reinforcement for illness behavior and as positive evidence of a psrchogenic process.

A post-hoc analysis using increased school absence as an inclusion eriteria can be applied to the present data. Table 9 shows that four of the subjects in the operant learning model (OP2, OP3, OP5, OP8) were absent from school more than the national average of 5.7 dars (Fowler et al., 1985). Three of the four subjects had decreases in the number of days missed from school or sick room visits during the relaxation treatment, and improvements on many of the other treatment outcome measures (see Table 13). Based on this post-hoc analysis, there appears to be some support for the use specific positive evidence of learning process li.e. negative reinforcement) with a relaxation and parent instruction treatment. Further research is needed to prospectively identify specific indicators of the learning process in the development and mantenance of RAP and to design and test treatments targeting this process.

The outcome results of the relaxation and parent instruction treatment for the nonconstipated subjects appear 
to be discrepant from the results of previous studies which utilized psychological approaches to RAP treatment; however there are some procedural differences which may account for some of this discrepancy. In their multicomponent cognitivebehavioral treatment, Sanders et al. (1989) utilized three components that were similar to the components of the present operant learning treatment: a) self-monttoring of pain; b) teaching parents to respond to their children's pain behavior by prompting and redirecting the children into a distracting activity; and c) teaching children relaxation. However, unlike the present study, they included a cognitive self-control procedure and reinforcement for absence of pain complaints below a criterion. The latter component, an operant technique targeting pain complaints, is similar to the approach of the two single case studies by Miller and Kratochwill (1979) and Sank and Biglan 11974), which were both effective in reducing pain complaints. One of the potential problems with interpreting the results of these studies is that it becomes unclear whether the resulting change was due to the child underreporting pain episodes or to actual reductions in the experience of pain.

The approach of the present study was not to target pain complaints, or to teach children to underreport pain, but to attempt to change the contangencies of their pain complaints by changing the parent-child interaction from 
possible inadvertent reinforcement of pain complaints to encouragement of coping. As mentioned above, it is not possible to determine how effective the present study was at actually changing the contingencies of pain complaints. It could be that, in the present study, the approach to changing the contingencies was too indirect and, therefore. not a powerful enough treatment. Perhaps targeting the source of the resnforcement more directly would be a more powerful technique. For example. Finney et al. (1989) required participation in routine activities for chidren who missed school or other activities as a result of the stomach pain. This approach is different from the present study but has the same function, that 13 , to change the contingencies thought to be maintaining the RAP symptoms The approach used in Finney et al. (1989) may be more powerful because it more directly addresses the problem by removing any negative reinforcement for avoldance.

\section{Other Issues}

In addition to considering the specific effects of each treatment within the two etiological models, there was some evidence to suggest that more than one factor may be operative in some children with RAP. In one subject with symptoms of constipation (C3), the frequency dropped during the relaxation treatment by more than $50 x$ from the first three weeks to the last three weeks of treatment isee Figure 
1). The relaxation treatment had the greatest effect on the child and parent-reported frequency of pain, with relatively little change in the number of pain-free days or days missed from school. As discussed above, subject OP2 responded to the fiber treatment with reductions in the frequency of stomachaches but relatively little change in the number of days missed from school. School absences were subsequenily reduced after the introduction of the relaxation treatment. One speculation is that learning, stress, and constipation may be involved; some stomachaches may be associated with environmental factors, whlle others are in response to physiological factors.

One assumption of the present study was that chlidren with a diagnosis of RAP are not a homogeneous group and that different mechanisms may be operating within different subgroups of RAP children. Several etiological models of RAP have been proposed to explain the mechanisms involved in the development and maintenance of RAP but no one model has been able to adequately account for the symptoms of all children with RAP. Traditionally, RAP symptoms have been classified as elther organic or psychogenic, that is, the absence of organic pathology has led to the assumption that the basis of RAP is psychogenic (Barr and Feuerstein, 1983; MCGrath et a). 1983). In following Apley's (1975) criteria for a diagnosis of psychogenic abdominal pain (1.e. negative 
evidence against organic disease and positive evidence of a psychogenic process). Barr and Feuerstein (1983) offered an alternative clinical framework for categorizing children with RAP. They proposed three groupings: an organic group which displays positive evidence of a pathologic organic process; a psychogenic group which displays positive evidence of a psychogenic process; and a dysfunctional group which lack positive evidence of an organic or psychogenic process.

This dysfunctional category implies that there may be some physiological or environmental mechanisms of RAP that are not well understood or are yet to be identified.

Constipation as a result of delayed bowel transit time and abnormal distal bowel contractions mar be one such mechanism. When more is known about the underlying phrsiologr of this subgroup of children with RAP, the organic mechanism can be identified and treated.

Alternately, more may be learned about the envionmental factors involved in the development and maintenance of RAP. Eventually, when more is known about the causal mechanisms involved in RAP, the diagnosis of RAP, be better defined with more specific inclusion criteria; all case of RAP will be classified as arganically based, such as lactose intolerance or constipation, psychologically based and recelve a 
diagnosis of somatization disorder, or some combination or interaction of organic and psychological factors.

Until more is understood about the role of potential physiological mechanisms in some children with RAP, it is difficult to be certain whether the basis for RAP is psychogenic for a given child. However, there are environmental factors which may constitute positive evidence of a psychogenic process. One factor that was discussed earlier is evidence of the reinforcement process, such as increased school absence as a result of stomachaches. Other environmental factors have not been addressed in the present study. Several studies have implicated the role of modeling in the development and maintenance of RAP (Christensen and Mortensen, 1975; Osborne, Hatcher \& Richtsmeier, 1989: Oster, 1972); however, there has been little theoretical speculation or treatment outcome data to assist the clinician in incorporating assessment data of modeling influences into treatment design. Family dysfunction has also been identified as a possible psychogenic factor in somatoform disorders (Mullins \& Olson, unpublished manuscripil; however, components of a family systems model and proposed treatment approaches from this model awat empirical validation.

The generality of the present findings may be somewhat limited in that the families in the current sample were all 
living relatively functional lives. To date, treatment outcome data on RAP has been with physician referred or self-referred community samples which tend to have less severe psychological problems than hospitalized patients (Feldman, 1986). The more severe cases may require more comprehensive conceptual models to understand the development and maintenance of RAP symptoms.

In conclusion, the present study represents the first systematic attempt to target the specific presenting symptoms of children with RAP with etiologically-based treatments. Initial support was obtained for the effectiveness of a dietary fiber treatment for children with symptoms of constipation. Indirect support was obtained for the role of constipation as a etiological process in the development and mantenance of RAP. Some support was obtained for the effectiveness of teaching children to relax and teaching parents to encourage coping for some children without symptoms of constipation. More research is needed to further identify psychogenic processes in the development and maintenance of RAP and to develop effective treatments that target these processes. 


\section{REFERENCES}

Achenbach, T. M. \& Edelbrock, C. S. (1979). The child behavior profile: II Boys aged $12-16$ and girls aged $E-$ 11 and 12-15. Cournal of Consulting and cilmical Psychology, 47, 223-233.

Almy, T. P. (1951). Experimental studies on the irritable colon. American Journal of Medicine, 9. 60-76.

American Psychiatric Association. (1987) Diagnostis and statistical manual of mental disorders i3rd ed. - rev. I Washington, DC: Author

Andrasik, F., Blake, D. D., \& McCarran, M. S, 119861. A biobehavioral analysis of pediatric headache. In $N$. A. Krasnegor, J. D. Arasteh, and M. F. Cataldo IEds.! Child health behavior: A behavioral pediatrics perspectsve. (pp. 394-434) New York: John Wiley \& Sons.

Apley, J. \& Naish, N. (1958). Recurrent abdominal pains: A field survey of 1,000 school children. Arehives of Disease in Childhood, $33,165-170$

Apley, J. (1959). The child with abdominal palns oxford Blackwell Scientific.

Apley. J. (1975). The child with abdominal palns (2nd ed.1. Oxford: Blackwell Scientific.

Apley, J. \& Hale, B. (1973). Children with recurrent abdominal pain: How do they grow up? British Medical journal. 3, 7-9.

Apley, J., Haslam, D. R., \& Tulloch, C. (1971) Fuplllary reaction in children with recurrent abdominal pain Archives of Disease in Childhood, 46, 337-340.

Barr, R. G. \& Feuerstein, M. (1983). Recurrent abdominal pain syndrome: How appropilate are our basic clinical assumptions? In P. J. Macrath \& P. Firestone IEds. Pediatric and adolescent behavioral medicine: Issues in treatment. New York: Springer

Barr, R. G., Levine, M. D. \& Watkins, J. B. (1979) Recurrent abdominal pain of childhood due to lactose intolerance. New England Journal of Medicine. 300 (26). 1449-1452.

Bayless, T. M. \& Huang, S. S. (1971). Recurrent abdominal pain due to milk and lactose intolerance in school-aged children. Pediatrics, 47, 1029-1032. 
Beck, A. T., Ward, C. H. Mendelson, M., Mock, J. \& \& Erbaugh, J. (1961). An inventory for measuring depression. Arohives of General Psychiatry, 4, 561-571

Benson, H. Klemchuk, H. P., \& Graham, J. R. (1974). The usefulness of the relaxation response in the therapy of headache. Headache, 14, 49-52.

Blanchard, E. B. \& Ahles, T. A. (1979). Behavioral treatment of psychophysiological disorders. Behavior Modification, 3, 518-549.

Browning, R. M. (1967). A same-subject design for simultaneous comparison of three reinforcement contingencles. Behaviar Research and Therapw, 5. 237243 .

Chasen, R. Tucker, H. Palmer, D., Whitehead, W. \& Schuster, M. (1982). Colonic motility in irritable bowel syndrome and diverticular disease. Gastroenterology, 8Z, 1031. Abstract.

Christensen, M. F. (1986). Recurrent abdominal apin and dietary fiber American Journal of Disease in Children. 140, $738-739$.

Christensen, M. F. \& Mortensen, O. (1975). Long-term prognosis in children with recurrent abdominal pain. Archives of Disease in Childiood, 50, 110-114.

Connell, A. M., Jones, F, A. \& Rowlands, E. N. (1965). Motility of the pelvic colon Part IV. Abdominal pain associated with colonic hypermotility after meals. Out. 6. $105-112$.

Corazziari, E., Cucchiara, S. Stalano, A. Romaniello, C., Tamburrin1, O. Torsol1, A. \& Auricchio, S. (1985) Castrointestinal transit time frequency of defecation. and anorectal manometry in healthy and constipated children. Journal of Pediatrics, 106 (31, 379-382.

Dimson. S. B. (1971). Transit time related to clinical findings in children with recurrent abdominal pain Pedsatrics, $47\{4\}, 666-674$.

Dunn-Gejer, B. J., MeCrath, P. J., Rourke, B. P., Latter, J. \& D'Astous, J (1986). Adolescent chronic pain. The ability to cope. Pain. 26, 23-32

Edwards. M. C. \& Neff. D. F. (1987). The roie of learning in the develapment and mantenance of hioh-perception psychophrsiologicsl disorders. Unpublished master's thesis. Virginia Polytechnic Institute and State University, Blackeburg, VA. 
Feldman, W (1986). Reply to Christensen. American Journal of Disease in Children, 140, 739

Feldman, W. McCrath, P. J. Hodgson, C., Ritter, H., \& Shipman, R. T. (1985). The use of dietary fibre in the management of simple childhood idiopathic recurrent abdominal pain: Results in a prospective double blind randomized controlled trial. American Journal of Diseases of Children, 139, 1216-1218

Feuerstein, M. Barr, R. C., Francoeur, T. E., Houle, M. \& Rafman, S. (1982). Polential biobehavioral mechanisms of recurrent abdominal pain in children. P\&1n, 13, 287298.

Finney, J. W., Lemanek, K. L., Cataldo, M. F., Katz, H. P. \& Fuqua, R W. (1989). Pediatric psychology in primary care: Brief targeted therapy for recurrent abdominal pain. Behavior Therapy, 20, 284-291.

Fowler, M. G., Johnson, M. P., \& Atkinson, S. S. (1985) School achievement and absence in children with chronic health conditions. The Journal of Pediatrics, April, 683-687.

Harvey, R. F. Pomare, E. W. \& Heaton, K. W. (1973). Effects of increased dietary fibre on intestinal transit. Lancet. 1, 1278-1280

Hersen. M\& Barlow, D.H. 11984). Single case experimental designs: Strategies for studying behavior change. Elmsford, New York: Pergamon.

Hodges, K., Kline, J. J., Barbero, C., \& Flanery, R, (1984) Life events occurring in families of children with recurrent abdominal pain. Journal of Psychosomatic Research, 28 (3), 185-188.

Hodges, K. Klıne, J, J., Barbero, G. \& Flanery, R. (1985a). Depressive symptoms in children with recurrent abdominal $p a i n$ and in their families. Journal of Pediatrics, 107 (4), 622-626.

Hodges, K. Kline, J. J., Barbero, C. \& Woodruff, C. (1985b). Anxiety in children with recurrent abdominal pain and their parents. Psychosomatics. 26 1111. 859866.

Jacobsen, E. (1939). Progressive relaxation. Chicago I11. : University of Chicago Press

Kazdin. A. R. (1980). Research Design in Clinical Fsychologs. New York: Harper \& Row. 
Kazdin, A. R. \{1984\}. Statistical analysis for single-case experimental designs. In $M$. Hersen and $D$. $H$. Bariow (Eds.) Single case experimental designs: Strategles ror studying behavior change. Elmsford, New York: Fergamon

Kopel, F. B., Kim, I. C. \& Barbero. A. J. 11967). Comparison of rectosigmoid motility in normal children, children with recurrent abdominal pain, and children with ulcerative colltis. Pediatrics, 39, 539-545.

Kovacs, M. (1978). Children's depression inventory (CDi) Unpublished Manuscript. University of Pitlsburgh

Latimer, P. R. (1981). Irritable bowel syndrome: A behaviaral model. Behavior research and therapy, 19 , 475-483.

Latimer, P., Sarna, S., Cambell, D., Latimer, M. Waterfall, W. \& Daniel, E. E. (1981), Colonic motór and myoelectrical activity: A comparative study of normal subjects, psychoneurotic patients, and patients with irritable bowel syndrome Castroenterology . 80. 893901 .

Levine M. D. \& Rappaport, L. A. (1984). Recurrent abdominal pain in school children: The loneliness of the Longdistance physician. Fediatsio ClinIES of North dmeriag. 31 (5). 969-991.

Lebenthal, E. Rossi, T. M., Nord, K. S. \& Bransk1, D (1981). Recurrent abdóminal pain and lactose absorption in children. Pediatrics, 67 $(6), 828-831$.

Liebman, W. M. (1979). Recurrent abdominal pain in children Lactose and sucrose intolerance, a prospective study. Pediatrics. 64 (1). 43-45.

Mash, E. J. \& Terdal, L. (1973). The response-class malrix: A procedure for recording parent-child interactions. Journal of Consulting and Clinical Psrchology, 40 il. $163-164$.

McCrath, P. J. \& Feldman, W. (1986), Clinical approach to recurrent abdominal pain 1 children. Developmental and Behavioral Pediatrics, $7(1), 56-61$.

McCrath, P. J., Goodman, J. T. Firestone, P., Shipman, R. \& Peters, S. (1983) Recurrent abdominal pain. A psychogenic disorder? Archives of Disease in Childhood. 58, 888-890.

Michener. W. M. 19811 . An approach to recurrent abdominal pain in children. Primary care, 8, 277-283. 
Milla, P. J. (1988). Gatrointestinal motility disordere in children. Pediatric Cinies ot North America. 35 (2). $311-330$.

Miller, A. J. \& Kratochwill, T. R. (1979). Reduction fo frequent stomachache complaints by time out Behavior Therapy, 10, 211-218

Miller, N. E. (1977) Effect of learning on gastrointestinal functions. Clinies in castroenterologx, 6 (3). 533-546

Mullins. L. L. \& Olson. R. A. (1989). What is so hysterial about conversion reaction?: Familial factors in the etiology, maintenance and treatment of somatoform disorders in children. Unpublished manuscripi

Nietzel, M. T. Russell, R. L., Hemmings, K. A. \& Gretier. M. L. (1987). Clinical significance of psychotherapy for unipolar depression: A meta-analytic approach to social comparison. Journal of Consulting and Clinical Psychology, 55 (2), 156-161.

Osborne, R. B., Hatcher, J. W. \& Rlchtsmeler. A. (1989). The role of social modeling in unexplained pediatric pain. Journal of Rediatric Psychology, 14, 43-61.

Oster, J. (1972). Recurrent abdominal pain, headache and $1 \mathrm{imb}$ pains in children and adolescents. Pediatrics. 50 (3), 429-436.

Poole, S. R. (1984). Recurrent abdominal pain in childhood and adolescence. Amerlean Famlly Phrsician, $30(2)$. $131-137$.

Raymer, D., Weininger, O., \& Hamllton, J. R. (1984). Psychological problems in children with abdominal pain Lancet, 2, 439-440.

Routh, D. K. \& Ernst, A. R. (1984). Somatization disorder in relatives of children and adolescents with functional abdominal pain. Journal of Pediatric Psycholagy. 4. 427-437.

Rubin, L. S. Barbero. G. J. \& Sabınga. M. A. (19671. Pupillary reactivity in children with recurrent abdominal pain. Fsychosomatic Medicine, 29 111-120

Sanders, M. R., Rebgetz, M., Morrison, M., Bor, W. Cordor. A., Dadds, M. \& Shepard, R. [1989]. Cognitivebehavioral treatment of recurrent nonspecific abdominla pain in children: An analysis of generalization. Maintenance, and side effects Journal of Consultang and Clinical Psychology, 5? (2), 294-300 
Sank, L. I. \& Biglan, A (1974). Operant treatment of 3 asse of recurtent abdominal pain in a lo-year-old boy. Betraviar Theraps: 5, 677-63!.

Schuster, M. M. (1983). Irritable bowel syndrome: Applications of psychophysiological methods to treatment. In R. Holzl and W.E. Whitehead IEds. Psychophrsiology of the Castrointestinal Tract: Experimental and Clinical Applications. New York: Plenum Press.

Smucker, M. R., Craighead, W. E., Cralghead, L. W, \& Creen, B. J. (1984). Normative and reliability data for the Children's Depression Invemtory., 25-39.

Splelberger, C. D. (1973). State-Tralt Anxiets Inventory for Childien. Palo Alto, CA: Consulting Psrchological Press.

Stone, R. T.\& Barbero, C.J (1970) Recurrent abdominal pain in childhood. Pediatrics. 45 (5). 732-738.

Strickler, G. B. \& Murphy, D. B. (1979). Recurrent abdominal pain. American Journal of Disease in Childhood. 133. 486-489.

Turner, R. M. (1978). Recurrent abdominal pain in childhood Journal of the foral College of Ceneral Pratitioners. 28. $729-734$

Whitehead, W. E., Engel, B. T. \& Schuster, M. M. 119801. Irritable bowel syndrome: Physiological and psychological differences between diarrhea-predominant and constipation-predominant palients. Digestive Diseases and Sciences, 25 (6), 404-413

Whitehead. W. E. Winget, C. Fedoravicus, A. S., Wooley. S. \& Blackwell. B. (1982). Learned illness behavior in patients with irritable bowel syndrome. Digestive Diseases and Sciences, 27, 202-208

Whitehead. W. E. \& Schuster, M. M. (1985). Gastrointestinai disorders: Eehavioral and phrsiologieal hasis for treatment. Orlando: hcademic Fress.

Whitehead, W. E. (1986). Pediatric Gastrointestinel Disorders. In N. A. Krasnegor, J. D. Arasteh, and $M$. $F$ Cataldo (Eds.) Child health behavior: A behavioral pediatrics perspectibe. (pp. 537-555) New York: John Wlley \& Sons. 
APPENDIX A 


\section{Eailu Fecords}

ivek of:

Four t A times a dey terord:

i) how much your stomach hurts

2) how long the stomachache lasted

ance a day answer the three questinns at the right of the sheet.

\section{Pain Rating Saale}

Use the scale below to rate how much your stomachache hurt

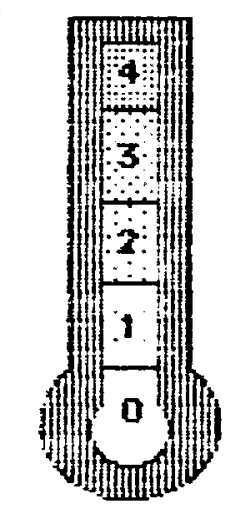

$4=$ Yery severe pain : it hurts so much that I san't do any thing

$\overline{3}=$ Severe pain $\quad$ it hurts and it is hard to pay attention but 1 can do simple things

$2=$ Moderate pain : it hurts but 1 can do most things

$1=$ Mild pain

: I don't notice the pain if I don't think about it

$0=$ Mo stomach pain

\begin{tabular}{|c|c|c|c|}
\hline DDIE\# & {$[\mathrm{ai}$} & 4 Manitarng Form & DE: \\
\hline Time & $\begin{array}{c}\text { Stomach Pain } \\
\text { Rating } \\
(0-4)\end{array}$ & $\begin{array}{l}\text { Check hou long } \\
\text { your stomach- } \\
\text { ache lasted }\end{array}$ & $\begin{array}{l}\text { Fill out this part each } \\
\text { day at bedtime: }\end{array}$ \\
\hline Breakfast & & 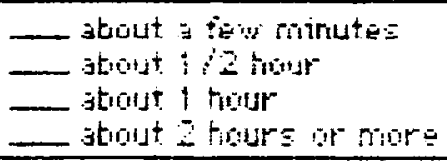 & \multirow{4}{*}{$\begin{array}{l}\text { 1. Did you hare a bowal } \\
\text { morement today? } \\
\text { How Many? } \\
\text { No } \\
\text { 2. What Yas it ljke: } \\
\text { Yatery } \\
\text { Smooth, normal } \\
\text { Bumpy and hard }\end{array}$} \\
\hline Lunch & & 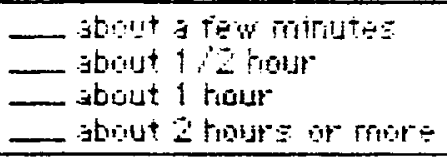 & \\
\hline Dinner & & 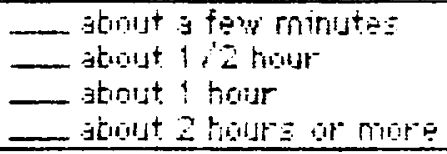 & \\
\hline Bedtime & & 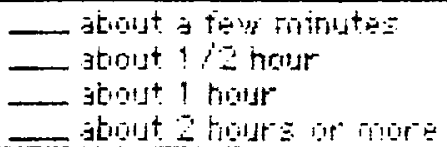 & \\
\hline
\end{tabular}


APPENDIX B 
Operational Definitions of Eowel Movement
Consistency Categorles

The following polnts were included in discussing with ohild and mother how to judge the consistency of the child's bowel movements:

Watery.

1) might feel watery when it comes out

2) the material tends to float in the wates rather than going to the bottom of the bowl

3) the material tends to break up into many smaller pieces rather than remairing formed

4) the water in the bowl may tura brown

Normal. If comes out on its own afier a mild push

2) not painful

3) goes to the bottom of the bowl

4) looks smooth, well-formed and not bumpy or pellet-like

Hard: 1) must push real hard to make it come out

2) mav be painful

3) goes to the bottom of the bow:

5) does not look smooth

6) looks bumpy or pellet-ilike 
APPENDIX $C$

121 


\section{2 \\ STOMACHACHE HISTORI: CHIld}

Niame.

Farent's Name: Age:

Sex. M F

Interviewer:

Date.

i. When did you irlst start having stomachaches? Use some event to he!p child conceptuailze time. !

2 Have your stomachaches gotten worse or better in ihe fasi 3 months? luse some event to help child concepiuai:ze time. I

3. When you have a siomachache are they usua! iy bai Enougt: to make you stop what you arg doung $l=g$ playing homework, school, etc.1? IES NO

4. Describe what your stomach pain feels like:

5. Do you have different "trpes" of stomach pair? "EE $\mathrm{NO}$ It yes, please describe

Show me where you hurt by putting an "Y" ln the giaces on the pictures where you feel pain. (Frompt: Is there anywhere else that you feel paln?)

6. Show me on this thermometer how much you hurt

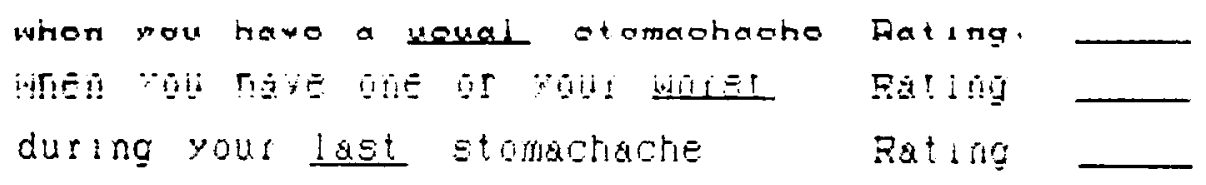

7 What do you do when you have a usual stomachache? : see prompts next pagel

What do you do when you have one of your wors: stomachache? 
What did you do when you had your last stomachache?

Prompts:
tell someone
cry
stop what she is doing $=$ Worst
lay down
go to bed

8. How often do you have stomachaches? Prompts:

$$
\begin{aligned}
& \text { more than once every day }- \\
& \text { once per day } \\
& \text { at least once per week } \\
& \text { at least once per month }- \\
& \text { less than once per month }-
\end{aligned}
$$

9. How long do your stomachaches usua!ly last?

$$
\text { Prompts: } \begin{aligned}
- & \text { a few minules } \\
\text { about a half hour } & \text { about one hour } \\
& \text { about two hours } \\
& \text { more than two hours }
\end{aligned}
$$

10. Do your stomachaches usually happen at particular times of the day or night?

What was the time of your last stomachache?

Frompts

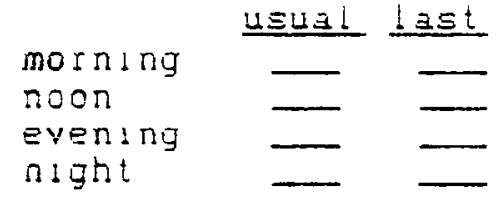

1. What are rou usually doing when you have a stomacnacne:

What where you doing during your last atomachache?

Prompts:

$$
\text { Lsuai Lasi }
$$

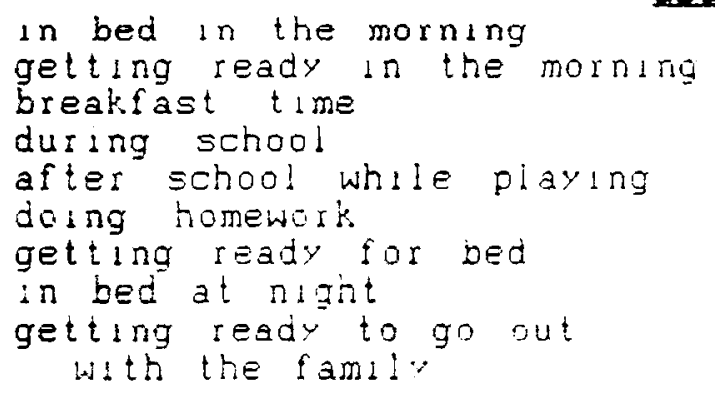


12. Who do you usually tell when you have a Etomachache?

13 Do vou ever tell this person that vou had a siomachache earlier in the day but now has stopped? YES NO

14. Does anyone ever ask you if you have a stomachache? YES NO If yes, who. when and how ofien:

15. Do you ever know that you are going to have a stomachache before you actually have one? i'Es NO if yes. how?

16. What do you do to make your stomachaches go away?

\begin{tabular}{ll}
\hline Prompts: & $\begin{array}{l}\text { lie down } \\
\text { ice pack } \\
\text { aspirins/tylenol Pepto-Bismol }\end{array}-$ Milk-or-inagneasa
\end{tabular}

17. What do other people do to try and make you stomachaches go away?

18. What works the best for making your stomachaches gi away?

19 When you have a stomachache, does anvthing else happen to you besides stomach pain? YES NO If yes. What and how often Frompts: Diarthea

Vomiting

Paleness

Dizziness

Constipation
Headache
Fever
Sleepiness
after attacks

20. Do you ever miss school because of your stomachacties? YES NO

21 Do vou ever miss other activities (Find out what activities the child is involved in, e.g. Scouts. gymnastics, going to a relatives or triends house!?

YES NO

if yes, what? 
22. How much milk do you drink and cheese and lce cream do you eat?

23. Are there certain foods that you do not eat any longer because of your stomachaches? 'IES NO If yes, which foods?

24. How often do go to the bathroom and have a bowel movement $(\# 2$, do-do $\}$ ? Prompts: more than once a day once a day every 2 days every 3 days every 4 days every 5 days

25. When you go poop, how hard is it for you lo make : come out?

Prompts: very easy, comes out by itgelf medlum, have to push a little very hard, have to push rea! hard

26. When you go to the bathroom, how big is your poop usual1y?

Frompts: Small

\section{Medium \\ $B \perp g$}

Do you every have really big ones? YES NO

If so how often?

Frompte: ali the time most of the time just somet 1 mes hardly ever

27. What is your do-do usually like?

Prompts: _ loose or watery

- smooth, normal. not bumpy

- hard bumpy

Is 1 it ever hard and bumpy? YES NO

If so. how of ten?

Prompts

all the time most of the time just sometimes hardly ever 
APPENDIX D

120 
Name:

Child'e Name: Relation.

Date: Age Sex: $M \quad F$

Interviewer:

1. When did stomachaches first become a problem for?

2. When did you first seek medical attention for 's abdominal problems?

3. How many stomachaches would you say ___ has had within the last 3 monthe?

4. Has di gotten worse or better in the past 3 months?

5. When has a stomachache are they tyelcall\% severe enough to affect his her activity leg. playing. homework, school, etc.l? YES NO

6. Describe the stomach pain reported by

Prompls: Cramplike _- Dull Ache __ Spasmodic

7. Are there severa! "types" of stomach pain reported by ? YES NO If yes, please describe:

Show me where s, he hutts by putting an " $x$ " in the places on the pictures where sihe feels pain

8. Show me on this thermometer how much rou think hurts.

when s/he has a typical stomachache. Rating when the pain is at its worst. Rating duling heI last stomachache Pa! 1 ng

9 What does do when sithe has a tyonal Etomachache? 
What does

do when sine has hisitier worst

stomachache?

What did

do when she had her last

stomachache?

Prompts

typical Worst Last

tel! someone

cry

stop what sihe is doing

lay down

go to bed

10. How of ten does

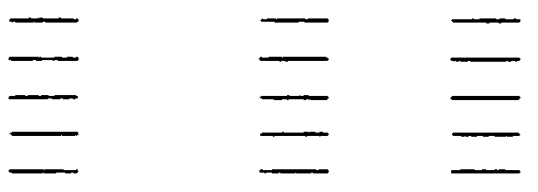

have stomachaches?

$\begin{array}{ll}\text { Prompts: } & \text { more than once every day } \\ \text { once per day } & \\ \text { at least once per week } & \\ \text { at least once per month } & \\ & \text { less than once per month }-\end{array}$

11. How long do the stomachaches usually last?

12. Do the stomachaches usually occur at particular times of the day or night?

What was the time of 's last stomachache? Prompte: usual last

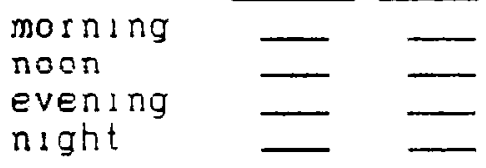

13. Do the stomachaches usually occur in any particular situation?

Where did 's last stomachache occur?

Prompts:
in bed in the morning
getting ready in the morning -
breakfast time
during school
after school while playing
doing homework
getting ready for bed




\section{9}

in bed at night

getting ready to go out

with the family

14. Who is usually told when has a stomachache?

15. Does ever tell you that a stomachache occurred earlier in the day but has now stopped?

YES NO

16. Do you ever ask If If s/he has a stumachacte? YES NO If yes, when and how of ten:

17. Are there certain behaviors you observe that indicate that has a stomachache?

18. Does know beforehand that a stomachache $1 \equiv$ developing? YES NO If yes, how?

ig. What does do to relleve the Etomachaches?

$\begin{array}{ll}\text { Prompts: } & \text { lie down } \\ \text { ice pack } & \text { Fepto-Bismo! } \\ \text { aspirinsitylenol Milk-af-Magnasia }\end{array}-$

20. List the methods you have tried to relleve 5 stomachaches.

21. Have you found any effective treatment for gtomachachea?

22. Has sour doctor told you the cause of _- stomachaches: YES NO If yes, what did sihe tell you?

23. Is on any medications? YES NO

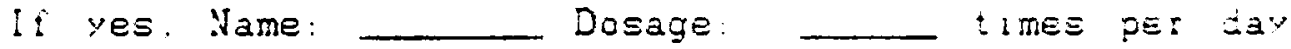

24. Has had other I1 hnesses? YEs NO If $y e s$, what and how many times? 
25. Does have other symptoms that accompany his/her stomachaches? YES NO If yes, what and how frequent?

Prompis:

Diarrhea

Vomiting

Paleness

Dizziness

Dilated pupils

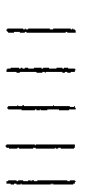

Constipation

Headache

Fever

Sleepiness

after attacks

26. Does miss school due to stomachaches? I'ES NO

If res, number of dars... in past month

in school year

27. Does miss other activities iscouts. gymastics, going to a relatives or friends housel? YES NO

If yes. what?

28. How much dalry products does consume?

29. Have you ever restricted 's diet in any way due to hisiher stomachaches? YES NO If yes. how?

Frompts: milk products

greasy foods
spicy foods $=$
other foods (11st) $=$

24. How often does have a BM?

Prompts: more than once a day

once a day

every 2 days

every 3 days

every 4 days

every 5 days

25. How hard is it for

to have a EM?

Prompte.

no strain

mild strain

much strain

26. How large is

$B M ?$

Prompte: Smal!

Medium

Large 


\section{1}

Does every have large BM's: iEs No

If so. how of ten?

Frompts: every time

most of the time occasiona!!y

rarely

27. What is the consistency of

BM usua!ly like?

Prompts: $\begin{aligned} & \text { loose or watery } \\ & \text { smooth, we!l formed not pellet-like }\end{aligned}$

- hard, pellet-like

Is $1 \mathrm{t}$ ever hard and pellet-like? YES No

If so, how often?

Prompts: every time

most of the time

occasionally

rarely 
APPENDIX E 


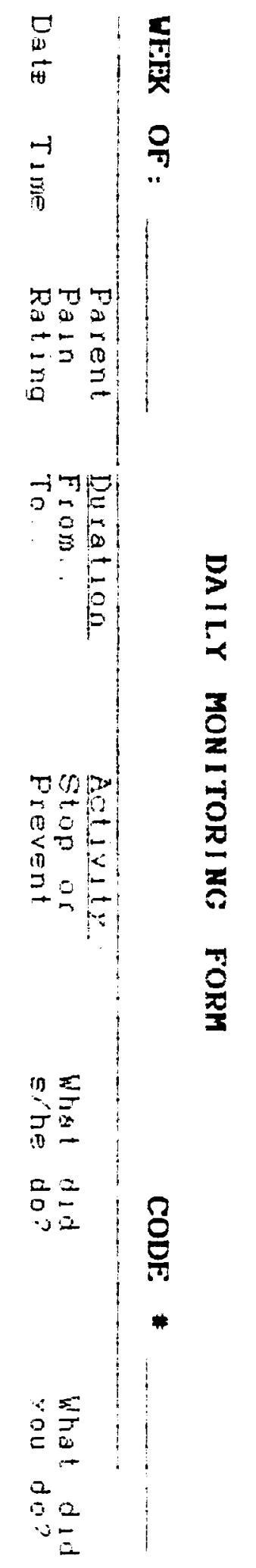


APFENDIX F

134 
HOME VISIT CHECKLIST

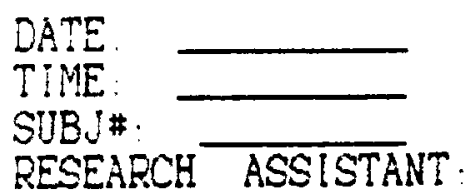

1. Montoring Sheets:
A. Were montoring sheets up to date iwithin 24 hoursl?
B. Were all the categories completed on the monitoring sheets?
C. Were the monitoring sheets easily accessible and in their usual location?

I! Fiber Treatment:
A. Did the child consume the recommended fiber within the last 24 hours?
B. Was the fiber consumed at the usual time?
c. Were the fiber cookies lor other foods easily accessible?

11i. Relaxation Treatment
A. Did the child practice the tape in the last 24 hours?
B. Did the child practice at the usual time?
C Was the tape easily accessible?

\section{Total Points}


APPENDIX G 


\section{RECURRENT ABDOMINAL PAIN \\ Parental Coneent for Client}

I understand that I am being asked to participate and to allow my child to participate in a research study designed to assess and treat factors related to recuryen: abdomina! pain. There will be no charge for the initia! evaluation and a maximum charge of three sessions at the hourly rate of the Psychologlcal Services Center. I understand that the assessment and treatment are complete:v voluntary and that we may discontinue participation at any time.

I understand that both my child and I will be asked to

1. be interviewed concerning m\% child's medical history anc histher problem with recurrent abdominal pair. and to complete several questionnalres to assese our current psychological status and behavior. Some of the questions nay be of a personal nature, and I am not required to answer questions where I am uncomfortable. This part should tate less than 60 minutes to complete

2. My child and I wlll record on a dally basis when sihe has pain and what s/he and I did about the pain. Daliy cards will be provided, and we will make dally recordings which will take no more than five minutes to complete. For at least two weeks prior to treatment. during treatment and for two weeks after treatment has terminated.

3. I give consent to have my chlld's physician contacted :0 request that s/he give medical information about my childs diagnosis and medical treatment

4. After we complete the above assessments, we wlll recelve a treatment program designed for children with recurrent abdominal pain and their families. Treatment session will last approximately 50 minutes in duration and the number of sessions could be as many as elght sessions

5. While we are in treatment a research assistant will make visits to our home to ask a few questions concerning the treatment. These visits will take place at a time agreed upon by us before treatment begins. The research assistant will make from 2 to 4 visits on randomly selected weekdays over the course of treatment. The visit should lake no nore than 15 minutes.

E. After finishing treatment. I will be contacted at 1.5 . 5 and 12 months post-treatment and be asked to keep one iweek of dally records and illl out an evaluation form as lollowup to the study 
There are no major risks associated with this study other than possible mild discomiort involved in answering some of the questions. I understand that it is my responsibility to advise the researchers of any medical problems that might arise in the course of the experiment.

As a result of our participation in this treatment, my child may experience relief from his/her stomach pain we may also benefit by gaining a better understanding of ourselves

Our participation in the study may be terminated at the discretion of the experimenter because

1. we fall to keep appointments and fall to make up missed appointments:

2. we fall to keep adequate dally records as described above: or

3. If other physical or psychological problems preclude out participation.

I understand that it is the intent of the investigator to maintain confidentiality. Information wili be kept in a secured flle. I will be seen at the Child Study Center and our participation as a client for this clinic will be kept confidentia!. However, if any information 19 presented that Indicates that I am a danger to myself or others appropriate therapeutic intervention will be taken

This research project has been approved by the Human Services Research Committee Questions about the project should be directed to the principle investigator Mark $b$ Edwards. 96:-5914: or Dr. Jack W Finne\%. 96:-6e70: Dr. Heien Crawford, chall of the Human Gervices Commitee, G6:6520; or Dr Charles Waring, chalr of the Instilutional Review Board, $961-5284$

I have read and do understand the above and freely consent to the procedures described. 
AFPENDIX H 
RECURRENT ABDOMINAL PAIN

Client Consent Form

You have been asked to help us find out what causes you: stomachaches (recurrent abdominal painl. We also want to test some new ways of treating stomachaches

We want you to come to the Child Study Center several times with your parents to talk to us. For abnut the first two or three times, we will ask you and your parents some questions about how you feel, about your stomachaches, and about your famly. After this, we will glve you and you parents ideas to help you have less stomachaches. During this $t$ me, we will ask you to keep track of your stomachaches on little cards we will give you. You will write on these cards every day while you are seeing is

We wll not hurt you, however, you may get a littie tired of answering so many questions. By doing the things that we tell you, your stomachaches may get better or go away.

If you have any questions, you should ask us if wou think you know what is going to happen to you and it 13 alright with you please write your name below.

Date Your Name

$\overline{\text { Date Whtness }}$ 
APPENDIS I 
Ptisician Evaluation Form

Re

Date:

1. Diagnosis of gastrointestinal problem:

2. What diagnostic tests have been coriducted?

urinanalysis

stool hemocult

$\mathrm{CBC}$

upper GI or other radiograph

- other (please specify)

3. Date of last complete physical examination:

4. Are there any medical evaluations or treatments that you feel this patient should receive?

No Yes

If yes. please specify:

Physician:

Address

Signature 
APPENDIX I 
PARENT FOLLOW-UP FORM

\section{Code \#}

1. Has your child stomachache condition gotten better. stayed the same, or gotten worse over the past month?

$$
\begin{aligned}
& \text { BETTER } \\
& \text { circle one) SAME } \\
& \text { WORSE }
\end{aligned}
$$

2. Rate the percentage of improvement s/he is curient:y experiencing in comparison to when s/he first presented to the trestiment study

$$
8
$$

If your child's condition has improved, what do you feel has brought about the change in hig/her condition?

3. Is your child currently using the treatment site learned in the study? If so. in what form?

4. Additional comments:

PLEASE RETURN THIS FORM ALONG WITH BOTH YOUR CHILD S AND YOUR ONE WEEK OF MONITORING FORMS IN THE ENCLOSED ENVELOPE THANK YOU' 


\section{The 6 page vita has been removed from the scanned document}




\section{The vita has been removed from the scanned document}




\section{The vita has been removed from the scanned document}




\section{The vita has been removed from the scanned document}




\section{The vita has been removed from the scanned document}




\section{The vita has been removed from the scanned document}

